\title{
ESTUdio DEL DESARROLLO DE ALEROS Y CUEVAS EN DIFERENTES REgIONES Y CONTEXTOS GEOLÓgicos DE LA ARgentina: HACIA UNA CARACTERIZACIÓN DE PATRONES Y PROCESOS
}

\author{
Cristian M. Favier Dubois ${ }^{\mathrm{a}}$, Débora M. Kligmann ${ }^{\mathrm{b}}$, Marcelo A. Záratec, Salomon \\ Hocsman $^{\mathrm{d}}$, Pilar Babot ${ }^{\mathrm{e}}$, Agustina Massigoge $^{\mathrm{f}}$, Bruno Mosquera $^{\mathrm{g}}$, Diego Rivero ${ }^{\mathrm{h}}$, Guillermo \\ Heider ', Gustavo A. Martínez', Pablo Ambrústolo ${ }^{\mathrm{k}}$, Manuel Carrera Aizpitarte', Julián P. \\ Gómez Augier ${ }^{\mathrm{m}}$, Juan P. Carbonelli ${ }^{\mathrm{n}}$, Dalila Herrera Villegas ${ }^{\circ}$ y Victor A. Durán ${ }^{\mathrm{p}}$
}

\section{Resumen}

Este trabajo forma parte de un proyecto cuyo objetivo principal consiste en realizar un análisis geoarqueológico de aleros y cuevas someras ubicados en diferentes regiones y contextos geológicos de la Argentina, con el fin de evaluar patrones y peculiaridades en el desarrollo de sus morfologias y estratigrafias. Dichos sitios constituyen ambientes restringidos con una dinámica particular que se forman, evolucionan, colmatan y/o colapsan de maneras diferentes y que deben estudiarse a escala regional para interpretar el registro arqueológico y tafonómico que contienen. En un mismo sector se pueden

a https://orcid.org/0000-0002-3693-2059 INCUAPA - CONICET, Facultad de Ciencias Sociales, UNCPBA, Olavarría, Argentina. cfavier3@gmail.com

b https://orcid.org/0000-0001-7322-4564. CONICET - Instituto de Arqueología, FFyL, Universidad de Buenos Aires, Argentina. kligmann@gmail.com

c https://orcid.org/0000-0002-9479-7289. INCITAP - CONICET, Universidad Nacional de la Pampa, Santa Rosa, Argentina.marcelozarate55@yahoo.com.ar

d https://orcid.org/0000-0002-3465-9730. ISES-CONICET, IAM, FCNeIML, Universidad Nacional de Tucumán, Argentina.shocsman@hotmail.com

e https://orcid.org/0000-0001-8382-7801. ISES-CONICET, IAM, FCNeIML, Universidad Nacional de Tucumán, Argentina.pilarbabot@yahoo.com

f https://orcid.org/0000-0001-9073-0303. INCUAPA - CONICET, Facultad de Ciencias Sociales, UNCPBA, Olavarría, Argentina. amassigo@soc.unicen.edu.ar

$g$ https://orcid.org/0000-0001-9513-1780. CONICET - Facultad de Ciencias Naturales y Museo, UNLP, La Plata, Argentina.bruno_mosquera@hotmail.com

h https://orcid.org/0000-0001-9815-9893. IEH - CONICET, Universidad Nacional de Córdoba, Argentina. ayampitin1@yahoo.com.ar

i https://orcid.org/0000-0002-5794-207X. CONICET-CCT San Luis, Departamento de Geología, Universidad Nacional de San Luis, Argentina.guillermoheider@hotmail.com

j https://orcid.org/0000-0001-8692-1502. IGCC - FCEyN, Universidad Nacional de Mar del Plata, Argentina. gamarti2003@yahoo.com.ar

k https://orcid.org/0000-0002-2140-1466. CONICET - Facultad de Ciencias Naturales y Museo, UNLP, La Plata, Argentina.pambrustolo@hotmail.com

1 https://orcid.org/0000-0002-1423-6722. IDECU - CONICET - FFyL, Universidad de Buenos Aires, Argentina. mcarreraaizpitarte@gmail.com

m https://orcid.org/0000-0003-2514-1750. Instituto de Geociencias y Medioambiente, UNT, FCNeIML, Tucumán, Argentina. julianpgaugier@hotmail.com

n IDECU - CONICET - FFyL, Universidad de Buenos Aires, Argentina. juanp.carbonelli@gmail.com

- https://orcid.org/0000-0001-8942-9185. INCUAPA - CONICET, Facultad de Ciencias Sociales, UNCPBA, Olavarría, Argentina.

p https://orcid.org/0000-0002-0534-0739. CONICET, Laboratorio de Paleoecología Humana, UNCUYO-FCEN, Mendoza, Argentina. duranvic2@gmail.com 
encontrar estas geoformas en diversas etapas de evolución, pero la velocidad de este proceso de cambio y sus características son poco conocidas para diferentes áreas del país. Es por ello que en esta contribución se analizan 24 casos de estudio localizados en distintas regiones para comenzar a evaluar patrones y procesos recurrentes. Asi, se han observado algunas regularidades interesantes en cuanto a los propios reparos (morfologías, tipos y dimensiones) y sus rellenos (características y cronologías) que comienzan a aportar información útil para su interpretación arqueológica y tafonómica.

Palabras clave: geoarqueología, aleros, cuevas, estudio comparativo, Argentina

\section{Abstract \\ STUDY ON THE DEVELOPMENT OF ROCKSHELTERS AND CAVES LOCATED IN DIFFERENT REGIONS AND GEOLOGIC CONTEXTS IN ARGENTINA: TOWARDS A CHARACTERIZATION OF PATTERNS AND PROCESSES}

This paper is part of a broader research project focused on analyzing rockshelters and shallow caves located in different regions and geological contexts in Argentina. The main goal is to evaluate patterns and peculiarities in the development of their morphologies and stratigraphies from a geoarchaeological perspective. These sites provide restricted environments with particular dynamics that form, evolve, fill up, and collapse in many different ways that need to be studied at a regional scale to interpret the archaeological and taphonomic records they contain. In one same area, these geoforms can be found at different steps of evolution; but the velocity of this change process, as well as their characteristics, are poorly known for different regions of the country. Thus, 24 case studies, located in different areas, are analyzed in this contribution to start evaluating patterns and recurring processes. So far, some interesting regularities have been observed, regarding the sites themselves (morphologies, types, and dimensions) as well as their sedimentary deposits (characteristics and chronologies). The preliminary results obtained, begin to offer useful information for their archaeological and taphonomic interpretation.

Keywords: Geoarchaeology, rockshelters, caves, comparative study, Argentina

\section{Introducción}

El origen de los reparos rocosos, su evolución temporal, los tipos de rellenos que contienen así como su eventual colapso, responden a factores de control cuyo análisis resulta clave para entender el uso humano de estos espacios en el pasado, su potencial cronológico, los procesos de sedimentación, las discontinuidades estratigráficas y las condiciones de preservación de materiales arqueológicos y tafonómicos (v.g. Strauss 1990; Bar-Yosef et al. 1992; Waters 1992; Farrand 2001a; Goldberg y Sherwood 2006). Entre los factores que controlan su desarrollo pueden destacarse la litología y estructura, el contexto geomorfológico, las condiciones climático-ambientales, el bioma, la actividad tectónica y el tiempo. Estos factores intervienen en los procesos de meteorización y erosión que inician y van modelando el crecimiento de una cavidad en la roca. En determinada etapa de su evolución, esta puede llegar a formar un refugio útil para los seres humanos, transformándose en un reparo rocoso, ya sea un alero o una cueva. Este reparo funciona como una trampa sedimentaria que no solo contendrá los materiales derivados de la roca de caja, sino también los aportes sedimentarios clásticos (partículas), químicos (sales, óxidos) y biológicos (restos vegetales, insectos, plumas, etc.) transportados hasta allí por el viento, el agua y/o la gravedad. A este relleno se suman los materiales (clásticos, químicos y biológicos) que puedan incorporar los seres humanos, la fauna y la flora a partir de habitar y/o utilizar el refugio, produciéndose una suma de aportes autóctonos (o endógenos) y alóctonos (o exógenos) que van a configurar el relleno del sitio, el cual constituye una evidencia, al menos parcial, de su historia de formación y ocupación. Finalmente, estos espacios pueden colmatarse, erosionarse o colapsar, perdiendo su relleno o quedando ocultos (Strauss 1990; Farrand 2001a; Borrero et al. 2007).

Este proyecto busca profundizar el conocimiento de los aspectos mencionados a través de un abordaje intra e interregional, en función de determinadas preguntas básicas y metodologías 
analíticas similares aplicadas al estudio de casos en el sur, centro y norte de Argentina. Entre estas preguntas se encuentran: ¿cómo se inicia y forma un alero/cueva?, ¿existen patrones recurrentes en su desarrollo?, ¿cómo se produce la sedimentación en ellos?, ¿cómo han sido utilizados por los seres humanos y la fauna?, ¿por qué hay hiatos temporales en sus rellenos?, ¿qué procesos posdepositacionales suelen afectarlos? y ¿`cómo se colmatan, erosionan o colapsan? Se considera que un esfuerzo de colaboración conjunta entre investigadores con experiencia en este tipo de sitios puede ayudar a clarificar estas cuestiones.

La hipótesis que guía este trabajo plantea que existen patrones y procesos recurrentes en los casos analizados, a pesar de sus particularidades. Su estudio comparativo permitirá evaluar alcances y limitaciones de estos espacios para la interpretación arqueológica y tafonómica. A partir de estos datos se analizarán algunas tendencias iniciales y se discutirán sus implicancias arqueológicas.

\section{Antecedentes}

Los estudios de aleros y cuevas son muy numerosos en el país y comienzan a ser planteados desde los inicios de la arqueología argentina (Ameghino 1880-1881). Las columnas estratigráficas de algunas cuevas han sido utilizadas como secuencias indicativas de cronologías culturales y cambios tecnológicos en varias regiones del país (v.g. Los Toldos, Cueva de Las Manos, Casa de Piedra, Gruta del Oro, Gruta de Intihuasi, Ongamira, Quebrada Seca 3, Inca Cueva 4, entre otras). Fue en la Gruta de Intihuasi (San Luis) donde se realizó la primera datación radiocarbónica para Sudamérica, publicada en 1957.

Mencionar todos los antecedentes de investigación disponibles para aleros y cuevas de Argentina resultaría casi imposible, por lo que se considerarán aquellos que provean datos útiles para este primer análisis de casos. En este sentido cabe mencionar que los estudios comparativos de aleros y cuevas a escala regional son escasos, destacándose aquellos referidos a los procesos de formación, estratigrafía y aspectos paleoambientales en reparos rocosos de Tandilia (Menghín y Bórmida 1950; Martínez 2007; Martínez et al. 2013) y a un estudio comparativo de abrigos rocosos en la costa norte de Santa Cruz (Zubimendi y Ambrústolo 2016). También existen antecedentes de estudios geoarqueológicos explícitos para casos particulares de aleros y cuevas que han introducido algunas de las discusiones que aquí se presentan (v.g. Etchichury 1975; Favier Dubois 1998; Pereyra y Guráieb 1998; Eugenio 1999; Scasso y Eugenio 1999; Zárate et al. 2000; Barberena et al. 2006; Borrero et al. 2007; Kligmann 2009; Mehl y Franco 2009; Mosquera 2015; Favier Dubois 2019).

\section{Aleros y cuevas: algunas definiciones}

En este trabajo se utiliza «reparo rocoso» como un término general amplio que comprende distintas formas de aleros (incluyendo paredones rocosos) y cuevas (incluyendo "gruta»). Por lo general, los aleros son más anchos que profundos mientras que las cuevas son más profundas que anchas. Sin embargo, en la realidad se trata de un continuum por lo que hay aleros profundos y cuevas someras que convergen en una zona «transicional». Cabe aclarar que el término «abrigo» es sinónimo de alero y se utiliza también en portugués (abrigo o sitio abrigado) así como en francés (abri) para este tipo de reparos rocosos (rockshelter en inglés).

Para la clasificación de los tipos genéticos de aleros y cuevas se ha utilizado la propuesta de Mentzer (2017) que, si bien se refiere básicamente a aleros, es útil también para clasificar cuevas someras como las involucradas en esta investigación. De acuerdo con esta autora, existen dos tipos básicos de cavidades según su génesis: a) las primarias, donde estas nacen como tales (como ocurre con los tubos de colapso de lava) y b) las secundarias, producidas por procesos de meteorización superficial y subsuperficial, que resultan las más frecuentes. Estas últimas se dividen en varios subtipos (Tabla 1): 
Tabla 1. Subtipos de cavidades secundarias (adaptados de Mentzer 2017: 727).

\begin{tabular}{|c|c|c|}
\hline & $\begin{array}{l}\text { Subtipos de cavidades } \\
\text { secundarias }\end{array}$ & Características \\
\hline 1 & Cársticas & Producidas primordialmente por disolución de rocas calcáreas \\
\hline 2 & Etchform & $\begin{array}{l}\text { Derivadas de la meteorización de rocas cristalinas o clásticas de grano } \\
\text { grueso (básicamente granitos) en subsuperficie }\end{array}$ \\
\hline 3 & $\begin{array}{l}\text { Pie de escarpa y } \\
\text { carst superficial }\end{array}$ & $\begin{array}{l}\text { Generadas en todo tipo de rocas por meteorización, disolución química } \\
\text { y/o actividad biológica en la base de escarpas }\end{array}$ \\
\hline 4 & $\begin{array}{l}\text { Tafoni y cavidades } \\
\text { por cascajos }\end{array}$ & $\begin{array}{l}\text { Generadas por meteorización salina y desprendimiento de cascajo en ro- } \\
\text { cas cristalinas o clásticas de grano grueso expuestas en superficie }\end{array}$ \\
\hline 5 & Abrasión y arrastre & $\begin{array}{l}\text { Generadas por flujos ácueos (fluviales, lacustres y marinos), glaciales y eó- } \\
\text { licos cargados de partículas o por la depositación de bloques movilizados } \\
\text { por agua o glaciares, pueden ser originadas en cualquier litología }\end{array}$ \\
\hline 6 & Tectónicas & Generadas por fallamiento en cualquier litología \\
\hline 7 & Pseudocársticas & $\begin{array}{l}\text { Generadas por meteorización diferencial o socavamiento en sedimentos } \\
\text { semiconsolidados }\end{array}$ \\
\hline
\end{tabular}

Las cavidades más comunes, al menos fuera de las regiones cársticas, son las desarrolladas en pie de escarpas y los tafoni. En el primer caso, la meteorización ocurre en la base de afloramientos rocosos y escarpas (v.g. Cueva de las Manos como sitio conocido en la Patagonia Argentina) o al pie de bloques de algunos metros de altura. En este contacto, la presencia de mayor humedad (retenida por el suelo y la vegetación), a veces combinada con la acción mecánica y química de plantas y otros organismos, conduce a la alteración de las rocas en un proceso que progresa hacia arriba a través de diferentes tipos de meteorización (McDonald y Twidale 2011). Esto da origen a la formación de escotaduras y/o cavidades alargadas en ese contacto (Fig. 1A).

Los tafoni (en singular tafone) son cavidades semiesféricas de distintos tamaños que se desarrollan en superficies rocosas de variadas litologías (a excepción quizás de rocas foliadas), pero que no se restringen a contactos, sino que ocupan diversas posiciones en los afloramientos (Fig. 1B). Se consideran poligenéticos, resultado de procesos de desagregación mecánica y desintegración química por meteorización y, secundariamente, por acción de la erosión (Turkington 2004; Groom et al. 2015; Chen et al. 2019). Las diferencias microclimáticas creadas en el reparo interior de los tafoni pueden acelerar los procesos de meteorización, reforzados por una retroalimentación positiva (Turkington y Phillips 2004). Estas cavidades se desarrollan con mayor frecuencia en ambientes áridos y en sectores costeros (Goudie 2004; Mentzer 2017).

\section{Materiales y métodos}

\subsection{Materiales}

En esta primera etapa se analizan en forma comparativa 24 casos de estudio de diferentes regiones del país, tomando en cuenta los tipos de reparo a los que corresponden de acuerdo con su origen y su morfología, así como las características y cronologías de los rellenos involucrados. Estos casos provienen de 16 investigadores que aceptaron participar en el proyecto y que aportaron información de sitios correspondientes a su región de trabajo. No obstante, la investigación está abierta a la incorporación de nuevos reparos rocosos que brinden investigadores con interés en sumarse a 


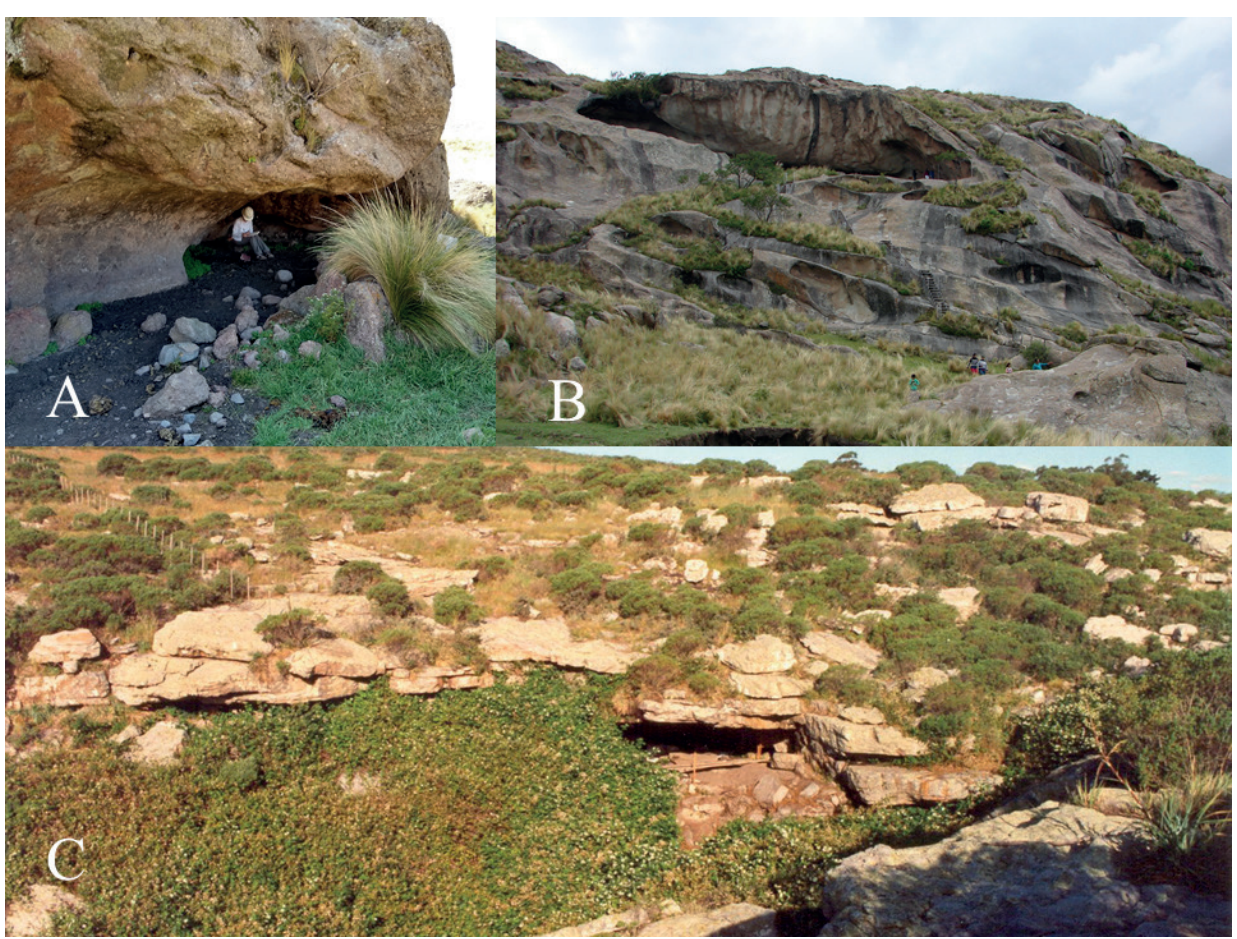

Figura 1. A. Desarrollo de un típico alero de pie de escarpa, ignimbritas del cerro El Morro, San Luis (foto: D. Storchi Lobos). B. Tafoni en diferentes etapas de evolución en un frente rocoso de andesitas, Sierras de San Luis (foto: D. Storchi Lobos). C. Control estructural que se refleja en la morfologia de la Cueva Tixi, Tandilia, Buenos Aires (foto: D. Mazzanti).

la propuesta. De esta manera se ampliará la muestra analizada y asimismo se incluirán, a futuro, ejemplos publicados en la literatura arqueológica argentina.

La región denominada Noreste Argentino (NEA) y varias provincias (Chubut, Neuquén, La Pampa, San Juan, La Rioja, Tucumán, Santiago del Estero y Jujuy) no están consideradas en este primer estudio, a pesar de que varias de ellas cuentan con antecedentes relevantes (Cueva Huachichocana III, Inca Cueva 4 y Cueva Haichol, solo por mencionar algunos ejemplos). En el caso particular del NEA, cabe aclarar que los afloramientos rocosos en la región han sido poco estudiados y, además, son escasas las investigaciones arqueológicas desarrolladas, en comparación con las áreas restantes aquí consideradas. No obstante, se considera que los sitios seleccionados hasta el momento son suficientes para comenzar a poner a prueba las variables elegidas para el análisis geoarqueológico de aleros y cuevas de nuestro país, ya que reflejan una diversidad de situaciones para cada una de las variables consideradas. El objetivo es comenzar a identificar patrones y procesos generales en la evolución de los reparos rocosos, a pesar de la variabilidad registrada y de los posibles sesgos involucrados, que podrán reducirse a medida que avance el proyecto.

En la figura 2 se presentan los sitios analizados y su distribución dentro del territorio argentino.

Tanto en esta figura como en las tablas de resultados los sitios están ordenados por región, de sur a norte. En cada región se siguieron dos criterios para organizarlos: en primer lugar, se tomó en cuenta la provincia donde están ubicados y luego se consideró la latitud de cada caso. 


\begin{tabular}{|c|l|}
\hline 1 & Alero Cabeza de León 1 \\
\hline 2 & Alero Chorrillo Malo 2 \\
\hline 3 & Alero El Puesto 1 \\
\hline 4 & Cueva Maripe \\
\hline 5 & Alero El Triunfo \\
\hline 6 & Alero 4 Cañadón Torcido \\
\hline 7 & Alero 2 Punta Pórfido \\
\hline 8 & Cueva Amalia Sitio 2 \\
\hline 9 & Cueva Tixi \\
\hline 10 & Abrigo La Tinta \\
\hline 11 & Alero Agua de la Cueva SN \\
\hline 12 & Alero Dupuy \\
\hline 13 & Alero La Angostura 1 \\
\hline 14 & Gruta de Intihuasi \\
\hline 15 & Alero Los Morteros \\
\hline 16 & Alero La Enramada 3 \\
\hline 17 & Alero El Gaucho 1 \\
\hline 18 & Cueva Quebrada del Real 1 \\
\hline 19 & Cueva Abra del Toro \\
\hline 20 & Alero 12 \\
\hline 21 & Alero Peñas Chicas 1.1 \\
\hline 22 & Alero Peñas Chicas 1.7 \\
\hline 23 & Alero 1 Punta de la Peña 9 \\
\hline 24 & Alero La Gruta \\
\hline & \\
\hline
\end{tabular}

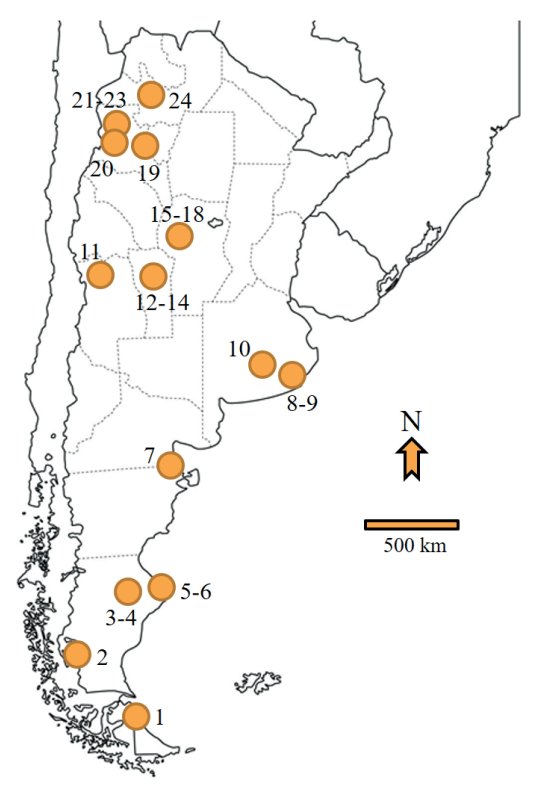

Figura 2. Mapa de distribución de los casos analizados (elaboración: C.M. Favier Dubois).

\subsection{Métodos}

Las variables elegidas para el estudio comparativo de aleros y cuevas fueron:

\section{A. Características generales}

\section{A.1. Nombre.}

A.2. Ubicación.

\section{B. Contexto geoambiental}

B.1. Bioma: vegetación y fauna, tanto autóctona como introducida.

B.2. Clima: precipitaciones, temperatura, vientos e insolación.

B.3. Geología: contexto geomorfológico, litología, estructuras y actividad sísmica.

\section{El sitio}
C.1. Morfología.
C.2. Dimensiones.
C.3. Orientación.

\section{Su relleno}

D.1. Características del relleno: composición, aportes endógenos y exógenos, estratigrafía y procesos posdepositacionales.

\section{D.2. Cronología.}

Para relevar estas variables se confeccionó una planilla con 30 ítems que fueron completados por los diferentes investigadores que participan del proyecto. A partir de la información obtenida se elaboró una base de datos general.

Si bien los objetivos y metodologías de trabajo de cada uno de los investigadores involucrados resultan algo diferentes, se buscó unificar información que pudiera ser comparable y que proveyera datos relevantes desde un punto de vista geoarqueológico. Debido a que el proyecto surgió con posterioridad a la excavación de los sitios que conforman la muestra, no todos los colegas 
registraron la misma información durante los trabajos de campo. En consecuencia, para algunas variables no es posible comparar en esta etapa todos los aleros y cuevas sino tan solo algunos de ellos. Por este motivo, si bien la ficha mencionada incluye 30 variables, en este primer acercamiento se analizaron 15 de ellas, a las que se sumaron otras seis que resultaron del cruce de información disponible en el cuestionario original. Las 15 variables restantes de este cuestionario serán integradas en futuros estudios.

A continuación, se detallan las 21 variables seleccionadas para este primer abordaje comparativo y se realizan las aclaraciones pertinentes para cada una:

\section{A. Características generales (variables 1 a 5)}

A.1. Nombre del sitio.

A.2. Ubicación: coordenadas geográficas, provincia, región y altitud.

\section{B. Contexto geoambiental (variables 6 a 11$)$}

B.1. Bioma: ambiente.

B.2. Clima: precipitaciones y temperatura media anuales.

B.3. Geología: litología (tipo de roca y nombre), estructuras de la roca de caja y procesos de meteorización estimados.

Para clasificar los sitios según el ambiente se utilizó la propuesta de Oyarzabal et al. (2018), basada en las unidades de vegetación definidas dentro de las provincias fitogeográficas clásicas reconocidas por Cabrera (1976), a las que brinda mayor detalle.

Los valores de precipitaciones y temperaturas medias anuales se basan en mediciones actuales. Si bien estos valores variaron a lo largo del Holoceno, representan una primera aproximación a las condiciones ambientales locales de carácter general.

Las variables estructuras de la roca de caja y procesos de meteorización estimados se presentan en opciones combinadas. En el caso de las diferentes combinaciones identificadas, el orden en que se menciona cada opción individual (en las figuras y tablas correspondientes) refleja el orden de importancia que cada una de ellas habría tenido en cada sitio.

El análisis de los procesos de meteorización estimados que habrían afectado la roca de caja tomó en cuenta las siguientes alternativas:

- MQ: meteorización química (v.g. hidrólisis, disolución, hidratación, oxidación), se trata de procesos vehiculizados por el agua.

- MS: meteorización física por sales (haloclastismo).

- MT: meteorización física por cambios de temperatura muy marcados entre el día y la noche (gran amplitud térmica), que por lo general baja de cero (termoclastismo, crioclastismo).

- MB: meteorización biológica, incluye procesos físicos y químicos (v.g. raíces, líquenes).

\section{El sitio (variables 12 a 15 )}

C.1. Tipo de cavidad / reparo.

C.2. Dimensiones: Ancho x profundidad x alto, tamaño y relación ancho/profundidad.

Para el análisis del tipo de cavidad/reparo, vinculado con su origen, se adoptó, con algunas modificaciones, el esquema elaborado por Mentzer (2017) (Tabla 1).

El ancho o abertura está medido de lado a lado, la profundidad de frente a fondo y el alto de la superficie del relleno, previa a la excavación, al techo.

Para la clasificación de los sitios por tamaño se elaboró una propuesta a partir de las siguientes categorías: 
- Pequeño: < a 8 metros de ancho o abertura.

- Mediano: $\geq$ a 8 metros y < a 16 metros de ancho o abertura.

- Grande: $\geq$ a 16 metros de ancho o abertura.

Asimismo, se calculó la relación ancho/profundidad ya que está íntimamente relacionada con la morfología del reparo, resultando de utilidad para determinar si se trata de un alero o de una cueva. Para analizar esta relación se propone el siguiente esquema clasificatorio:

- Alero: relación ancho/profundidad > a 1.

- Alero-cueva: relación ancho/profundidad = a 1 .

- Cueva: relación ancho/profundidad < a 1 .

D. Su relleno (variables 16 a 21 )

D.1. Características del relleno: profundidad máxima del relleno, proporción relativa de material endógeno, agentes involucrados en el aporte de material exógeno, rasgos pedogenéticos y restos orgánicos preservados.

D.2. Cronología: edad máxima obtenida en el relleno, en la mayoría de los casos cercana a la roca de base.

La profundidad máxima del relleno se midió desde la superficie hasta la roca de base o hasta los niveles alcanzados en la excavación. Estos últimos casos están indicados en las tablas correspondientes con el símbolo $>$ a X centímetros.

Para el análisis de la proporción relativa de material endógeno (procedente de la meteorización de la roca de caja durante el Holoceno) se utilizaron las siguientes opciones, a partir de una estimación cuantitativa en algunos casos y cualitativa en la mayoría de ellos:

- Bajo: $\leq$ al 30\%.

- Medio: > al 30\% y $\leq$ al $60 \%$.

- Elevado: > al 60\%.

Las siglas utilizadas para los restos orgánicos preservados son las siguientes: C: carbón, $\mathrm{H}$ : huesos, $\mathrm{V}$ : valvas de molusco, M: madera y restos vegetales, P: plumas y/o pelos y T: textiles.

\section{Resultados}

\section{A. Características generales (variables 1 a 5)}

Los sitios analizados se ubican entre los $25^{\circ}$ y $53^{\circ} \mathrm{S}$ y los $58^{\circ}$ y $72^{\circ} \mathrm{O}$ y presentan una gran amplitud altitudinal, que varía entre 15 y $4000 \mathrm{msnm}$ (Tabla 2). Estos abarcan cinco regiones y nueve provincias, siendo Patagonia, Sierras Centrales y Noroeste Argentino (NOA) las regiones con más casos de estudio y Santa Cruz y Catamarca las provincias más representadas en la muestra analizada (Tabla 2 y Fig. 3A). 
Tabla 2. Caracteristicas generales de los casos de estudio.

\begin{tabular}{|c|c|c|c|c|c|c|c|}
\hline \multirow{3}{*}{$\mathrm{N}^{\circ}$} & \multirow{3}{*}{$\begin{array}{l}\text { SITIO } \\
\text { (de sur a norte) }\end{array}$} & \multicolumn{5}{|c|}{ UBICACIÓN } & \multirow{3}{*}{ Referencias bibliográficas } \\
\hline & & \multicolumn{2}{|c|}{$\begin{array}{c}\text { Coordenadas } \\
\text { geográficas }\end{array}$} & \multirow{2}{*}{ Provincia } & \multirow{2}{*}{ Región } & \multirow{2}{*}{$\begin{array}{l}\text { Altitud } \\
(\mathrm{msnm})\end{array}$} & \\
\hline & & Latitud & Longitud & & & & \\
\hline 1 & $\begin{array}{l}\text { Alero Cabeza de } \\
\text { León } 1 \text { (CL1) }\end{array}$ & $53^{\circ} 18^{\prime} \mathrm{S}$ & $68^{\circ} 33^{\prime} \mathrm{O}$ & $\begin{array}{l}\text { Tierra del } \\
\text { Fuego }\end{array}$ & Patagonia & 50 & Favier Dubois 1998 \\
\hline 2 & $\begin{array}{l}\text { Alero Chorrillo } \\
\text { Malo } 2 \text { CHM2) }\end{array}$ & $50^{\circ} 29^{\prime} \mathrm{S}$ & $72^{\circ} 40^{\prime} \mathrm{O}$ & Santa Cruz & Patagonia & 235 & $\begin{array}{l}\text { Favier Dubois 1999; Franco } \\
\text { y Borrero } 2003\end{array}$ \\
\hline 3 & $\begin{array}{l}\text { Alero El Puesto } \\
1 \text { (AEP-1) }\end{array}$ & $47^{\circ} 53^{\prime} \mathrm{S}$ & $67^{\circ} 51^{\prime} \mathrm{O}$ & Santa Cruz & Patagonia & 94 & $\begin{array}{l}\text { Zárate et al. 2000; Mosquera } \\
2018\end{array}$ \\
\hline 4 & Cueva Maripe & $47^{\circ} 51^{\prime} \mathrm{S}$ & $68^{\circ} 56^{\prime} \mathrm{O}$ & Santa Cruz & Patagonia & 560 & $\begin{array}{l}\text { Miotti et al. 2007; Miotti } \\
\text { et al. 2014; Mosquera } 2015\end{array}$ \\
\hline 5 & Alero El Triunfo & $47^{\circ} 55^{\prime} \mathrm{S}$ & $66^{\circ} 29^{\prime} \mathrm{O}$ & Santa Cruz & Patagonia & 97 & $\begin{array}{l}\text { Zubimendi y Ambrústolo } \\
2016\end{array}$ \\
\hline 6 & $\begin{array}{l}\text { Alero } 4 \text { Cañadón } \\
\text { Torcido }\end{array}$ & $47^{\circ} 44^{\prime} \mathrm{S}$ & $65^{\circ} 57^{\prime} \mathrm{O}$ & Santa Cruz & Patagonia & 17 & $\begin{array}{l}\text { Ambrústolo y Ciampagna } \\
2015\end{array}$ \\
\hline 7 & $\begin{array}{l}\text { Alero } 2 \text { Punta } \\
\text { Pórfido (A2 PP) }\end{array}$ & $41^{\circ} 46^{\prime} \mathrm{S}$ & $65^{\circ} 00^{\prime} \mathrm{O}$ & Río Negro & Patagonia & 15 & $\begin{array}{l}\text { Favier Dubois 2019; Favier } \\
\text { Dubois et al. } 2020\end{array}$ \\
\hline 8 & $\begin{array}{l}\text { Cueva Amalia } \\
\text { Sitio } 2\end{array}$ & $38^{\circ} 03^{\prime} \mathrm{S}$ & $58^{\circ} 11^{\prime} \mathrm{O}$ & Buenos Aires & $\begin{array}{c}\text { Región } \\
\text { Pampeana }\end{array}$ & 93 & $\begin{array}{l}\text { Osterrieth et al. 2002; } \\
\text { Martínez et al. 2004; Bonnat } \\
\text { et al. } 2015\end{array}$ \\
\hline 9 & Cueva Tixi & $37^{\circ} 58^{\prime} \mathrm{S}$ & $58^{\circ} 04^{\prime} \mathrm{O}$ & Buenos Aires & $\begin{array}{l}\text { Región } \\
\text { Pampeana }\end{array}$ & 177 & $\begin{array}{l}\text { Mazzanti 1997; Martínez y } \\
\text { Osterrieth 2001; Martínez } \\
2007\end{array}$ \\
\hline 10 & Abrigo La Tinta & $37^{\circ} 36^{\prime} \mathrm{S}$ & $59^{\circ} 30^{\prime} \mathrm{O}$ & Buenos Aires & $\begin{array}{l}\text { Región } \\
\text { Pampeana }\end{array}$ & 288 & Rafuse y Massigoge 2019 \\
\hline 11 & $\begin{array}{l}\text { Alero Agua } \\
\text { de la Cueva SN }\end{array}$ & $32^{\circ} 37^{\prime} \mathrm{S}$ & $69^{\circ} 09^{\prime} \mathrm{O}$ & Mendoza & $\mathrm{COA}$ & 2900 & $\begin{array}{l}\text { Castro y Cortegoso 2010- } \\
\text { 2011; Lucero et al. 2006; } \\
\text { Durán et al. } 2020\end{array}$ \\
\hline 12 & Alero Dupuy & $32^{\circ} 59^{\prime} \mathrm{S}$ & $65^{\circ} 47^{\prime} \mathrm{O}$ & San Luis & $\begin{array}{l}\text { Sierras } \\
\text { Centrales }\end{array}$ & 1150 & Curtoni et al. 2017 \\
\hline 13 & $\begin{array}{l}\text { Alero La } \\
\text { Angostura } 1\end{array}$ & $32^{\circ} 58^{\prime} \mathrm{S}$ & $65^{\circ} 59^{\prime} \mathrm{O}$ & San Luis & $\begin{array}{l}\text { Sierras } \\
\text { Centrales }\end{array}$ & 1300 & $\begin{array}{l}\text { Carrera Aizpitarte 2017; } \\
\text { Cena Di Matteo et al. } 2018\end{array}$ \\
\hline 14 & $\begin{array}{l}\text { Gruta de } \\
\text { Intihuasi }\end{array}$ & $32^{\circ} 50^{\prime} \mathrm{S}$ & $65^{\circ} 57^{\prime} \mathrm{O}$ & San Luis & $\begin{array}{l}\text { Sierras } \\
\text { Centrales }\end{array}$ & 1560 & González 1960 \\
\hline 15 & $\begin{array}{l}\text { Alero Los } \\
\text { Morteros }\end{array}$ & $31^{\circ} 43^{\prime} \mathrm{S}$ & $64^{\circ} 51^{\prime} \mathrm{O}$ & Córdoba & $\begin{array}{l}\text { Sierras } \\
\text { Centrales }\end{array}$ & 2190 & Rivero 2017 \\
\hline 16 & $\begin{array}{l}\text { Alero La } \\
\text { Enramada } 3\end{array}$ & $31^{\circ} 43^{\prime} \mathrm{S}$ & $64^{\circ} 45^{\prime} \mathrm{O}$ & Córdoba & $\begin{array}{l}\text { Sierras } \\
\text { Centrales }\end{array}$ & 2076 & Rivero y Heider 2020 \\
\hline 17 & $\begin{array}{l}\text { Alero Arroyo } \\
\text { El Gaucho } 1\end{array}$ & $31^{\circ} 41^{\prime} \mathrm{S}$ & $64^{\circ} 45^{\prime} \mathrm{O}$ & Córdoba & $\begin{array}{l}\text { Sierras } \\
\text { Centrales }\end{array}$ & 1843 & $\begin{array}{l}\text { Rivero 2009, Rivero et al. } \\
2008\end{array}$ \\
\hline
\end{tabular}


Tabla 2. Caracteristicas generales de los casos de estudio.

\begin{tabular}{|c|c|c|c|c|c|c|c|}
\hline 18 & $\begin{array}{l}\text { Cueva Quebrada } \\
\text { del Real }\end{array}$ & $31^{\circ} 40^{\prime} \mathrm{S}$ & $64^{\circ} 53^{\prime} \mathrm{O}$ & Córdoba & $\begin{array}{l}\text { Sierras } \\
\text { Centrales }\end{array}$ & 1914 & Rivero et al. 2010 \\
\hline 19 & $\begin{array}{l}\text { Cueva Abra } \\
\text { del Toro }\end{array}$ & $26^{\circ} 58^{\prime} S$ & $66^{\circ} 00^{\prime} \mathrm{O}$ & Catamarca & $\mathrm{NOA}$ & 3000 & Carbonelli et al. 2019 \\
\hline 20 & Alero 12 & $26^{\circ} 55^{\prime} \mathrm{S}$ & $68^{\circ} 06^{\prime} \mathrm{O}$ & Catamarca & $\mathrm{NOA}$ & 4000 & $\begin{array}{l}\text { Kligmann et al. 1999; } \\
\text { Albino y Kligmann 2007; } \\
\text { Kligmann } 2009\end{array}$ \\
\hline 21 & $\begin{array}{l}\text { Alero Peñas } \\
\text { Chicas 1.1 } \\
\text { (PCh 1.1) }\end{array}$ & $26^{\circ} 01^{\prime} S$ & $67^{\circ} 21^{\prime} \mathrm{O}$ & Catamarca & $\mathrm{NOA}$ & 3550 & Hocsman y Babot 2018 \\
\hline 22 & $\begin{array}{l}\text { Alero Peñas } \\
\text { Chicas } 1.7 \text { (PCh } \\
1.7)\end{array}$ & $26^{\circ} 01^{\prime} S$ & $67^{\circ} 21^{\prime} \mathrm{O}$ & Catamarca & NOA & 3572 & Hocsman y Babot 2018 \\
\hline 23 & $\begin{array}{l}\text { Alero } 1 \text { Punta de } \\
\text { la Peña } 9 \text { (PP9) }\end{array}$ & $26^{\circ} 00^{\prime} S$ & $67^{\circ} 19^{\prime} \mathrm{O}$ & Catamarca & NOA & 3590 & $\begin{array}{l}\text { Babot et al. 2006; Winkel } \\
\text { et al. } 2018\end{array}$ \\
\hline 24 & Alero La Gruta & $25^{\circ} 11^{\prime} \mathrm{S}$ & $65^{\circ} 50^{\prime} \mathrm{O}$ & Salta & NOA & 3100 & Martel 2010a, 2010b \\
\hline
\end{tabular}

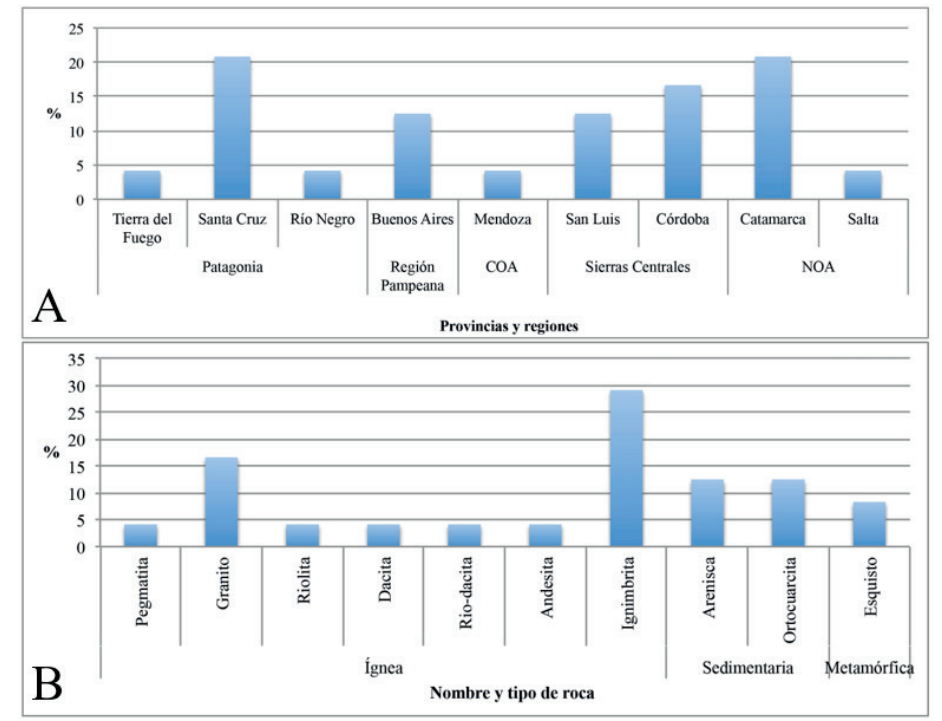

Figura 3. A. Distribución de los casos de estudio por provincias y regiones. B. Litología de los reparos rocosos analizados (elaboración: D.M. Kligmann).

\section{B. Contexto geoambiental (variables 6 a 11 )}

Los sitios analizados abarcan 10 ambientes (Tabla 3). Si se toma en cuenta cada una de las regiones, se puede observar que Patagonia es la región que presenta casos correspondientes a más tipos ambientales (cuatro), mientras que Sierras Centrales y el NOA presentan casos de dos tipos de ambientes y la Región Pampeana y el Centro Oeste Argentino (COA) solo de uno (Tabla 4). 
Tabla 3. Contexto geo-ambiental de los casos de estudio.

\begin{tabular}{|c|c|c|c|c|c|c|c|}
\hline \multirow{3}{*}{$\mathrm{N}^{\circ}$} & \multirow{3}{*}{$\begin{array}{l}\text { Sitio } \\
\text { (de sur a norte) }\end{array}$} & \multirow{3}{*}{$\begin{array}{c}\text { BIOMA } \\
\text { Ambiente }\end{array}$} & \multirow{3}{*}{$\begin{array}{c}\text { CLIMA } \\
\text { Precipita- } \\
\text { ciones }(\mathrm{mm}) \\
\text { y temperatura } \\
\text { media }\left({ }^{\circ} \mathrm{C}\right) \\
\text { anuales } \\
\end{array}$} & \multicolumn{4}{|c|}{ GEOLOGÍA } \\
\hline & & & & \multicolumn{2}{|c|}{ Litología } & \multirow{2}{*}{$\begin{array}{c}\text { Estructuras } \\
\text { de la roca } \\
\text { de caja }\end{array}$} & \multirow{2}{*}{$\begin{array}{l}\text { Procesos de } \\
\text { meteorización } \\
\text { estimados }\end{array}$} \\
\hline & & & & $\begin{array}{l}\text { Tipo de } \\
\text { roca }\end{array}$ & $\begin{array}{l}\text { Nombre de } \\
\text { la roca }\end{array}$ & & \\
\hline 1 & $\begin{array}{l}\text { Alero Cabeza de } \\
\text { León } 1 \text { (CL1) }\end{array}$ & $\begin{array}{l}\text { Estepa Húmeda } \\
47\end{array}$ & $250 / 5$ & $\begin{array}{l}\text { Sedimen- } \\
\text { taria }\end{array}$ & Arenisca & Homogénea & MS-MQ-MT \\
\hline 2 & $\begin{array}{l}\text { Alero Chorrillo } \\
\text { Malo } 2 \text { (CHM2) }\end{array}$ & $\begin{array}{l}\text { Estepa de } \\
\text { Coirón } 38\end{array}$ & $650 / 8$ & Ígnea & Dacita & Fracturas & MQ-MT-MB \\
\hline 3 & $\begin{array}{l}\text { Alero El Puesto } 1 \\
\text { (AEP-1) }\end{array}$ & $\begin{array}{l}\text { Estepa Arbustiva } \\
42\end{array}$ & $200 / 9$ & $\begin{array}{l}\text { Sedimen- } \\
\text { taria }\end{array}$ & Arenisca & $\begin{array}{l}\text { Diaclasas / } \\
\text { Fracturas }\end{array}$ & MQ-MT \\
\hline 4 & Cueva Maripe & $\begin{array}{l}\text { Estepa Arbustiva } \\
42\end{array}$ & $200 / 9$ & Ígnea & Ignimbrita & Fracturas & MQ-MT \\
\hline 5 & Alero El Triunfo & $\begin{array}{l}\text { Estepa Arbustiva } \\
42\end{array}$ & $200 / 10$ & Ígnea & Ignimbrita & $\begin{array}{l}\text { Homogénea / } \\
\text { Diaclasas }\end{array}$ & MQ-MS-MT \\
\hline 6 & $\begin{array}{l}\text { Alero } 4 \text { Cañadón } \\
\text { Torcido }\end{array}$ & $\begin{array}{l}\text { Estepa Arbustiva } \\
42\end{array}$ & $200 / 10$ & Ígnea & Ignimbrita & $\begin{array}{l}\text { Homogénea / } \\
\text { Diaclasas }\end{array}$ & MQ-MS-MT \\
\hline 7 & $\begin{array}{l}\text { Alero } 2 \text { Punta } \\
\text { Pórfido (A2 PP) }\end{array}$ & $\begin{array}{l}\text { Monte Estepa } \\
25\end{array}$ & $250 / 15$ & Ígnea & Riolita & $\begin{array}{l}\text { Homogénea / } \\
\text { Diaclasas }\end{array}$ & MS-MQ-MT \\
\hline 8 & $\begin{array}{l}\text { Cueva Amalia } \\
\text { Sitio } 2\end{array}$ & $\begin{array}{l}\text { Pampa } \\
\text { Pseudoestepa } 34\end{array}$ & $820 / 14$ & $\begin{array}{l}\text { Sedimen- } \\
\text { taria }\end{array}$ & $\begin{array}{l}\text { Ortocua- } \\
\text { rcita }\end{array}$ & $\begin{array}{l}\text { Diaclasas / } \\
\text { Estratificación }\end{array}$ & MQ-MB \\
\hline 9 & Cueva Tixi & $\begin{array}{l}\text { Pampa } \\
\text { Pseudoestepa } 34\end{array}$ & $820 / 14$ & $\begin{array}{l}\text { Sedimen- } \\
\text { taria }\end{array}$ & $\begin{array}{l}\text { Ortocuar- } \\
\text { cita }\end{array}$ & $\begin{array}{l}\text { Diaclasas / } \\
\text { Estratificación }\end{array}$ & MQ-MB \\
\hline 10 & Abrigo La Tinta & $\begin{array}{l}\text { Pampa } \\
\text { Pseudoestepa } 34\end{array}$ & $900 / 14$ & $\begin{array}{l}\text { Sedimen- } \\
\text { taria }\end{array}$ & $\begin{array}{l}\text { Ortocuar- } \\
\text { cita }\end{array}$ & $\begin{array}{l}\text { Diaclasas / } \\
\text { Estratificación }\end{array}$ & MQ-MB \\
\hline 11 & $\begin{array}{l}\text { Alero Agua } \\
\text { de la Cueva SN }\end{array}$ & $\begin{array}{l}\text { Altoandina } \\
\text { Estepa } 36\end{array}$ & $250 / 6$ & $\begin{array}{l}\text { Metamór- } \\
\text { fica }\end{array}$ & Esquisto & $\begin{array}{l}\text { Diaclasas / } \\
\text { Fracturas }\end{array}$ & MQ-MT \\
\hline 12 & Alero Dupuy & Chaco Bosque 7 & $700 / 17$ & Ígnea & Pegmatita & Fracturas & MQ-MB \\
\hline 13 & $\begin{array}{l}\text { Alero La } \\
\text { Angostura } 1\end{array}$ & Chaco Bosque 7 & $700 / 17$ & $\begin{array}{l}\text { Metamór- } \\
\text { fica }\end{array}$ & Esquisto & Fracturas & MQ-MB \\
\hline 14 & Gruta de Intihuasi & Chaco Bosque 7 & $550 / 12$ & Ígnea & Andesita & $\begin{array}{l}\text { Homogénea / } \\
\text { Fracturas }\end{array}$ & MQ-MB \\
\hline 15 & $\begin{array}{l}\text { Alero Los } \\
\text { Morteros }\end{array}$ & $\begin{array}{l}\text { Pastizal de } \\
\text { Altura } 8\end{array}$ & $800 / 8$ & Ígnea & Granito & $\begin{array}{l}\text { Homogénea / } \\
\text { Fracturas }\end{array}$ & MQ-MT-MB \\
\hline 16 & $\begin{array}{l}\text { Alero La } \\
\text { Enramada } 3\end{array}$ & Chaco Bosque 7 & $800 / 8$ & Ígnea & Granito & $\begin{array}{l}\text { Homogénea / } \\
\text { Fracturas }\end{array}$ & MQ-MT-MB \\
\hline 17 & $\begin{array}{l}\text { Alero Arroyo } \\
\text { El Gaucho } 1\end{array}$ & Chaco Bosque 7 & $800 / 8$ & Ígnea & Granito & $\begin{array}{l}\text { Homogénea / } \\
\text { Fracturas }\end{array}$ & MQ-MT-MB \\
\hline
\end{tabular}




\begin{tabular}{|c|c|c|c|c|c|c|c|}
\hline 18 & $\begin{array}{l}\text { Cueva Quebrada } \\
\text { del Real }\end{array}$ & $\begin{array}{l}\text { Pastizal de } \\
\text { Altura } 8\end{array}$ & $800 / 8$ & Ígnea & Granito & $\begin{array}{l}\text { Homogénea / } \\
\text { Fracturas }\end{array}$ & MQ-MT-MB \\
\hline 19 & $\begin{array}{l}\text { Cueva Abra } \\
\text { del Toro }\end{array}$ & $\begin{array}{l}\text { Prepuna Estepa } \\
6\end{array}$ & $175 / 15$ & Ígnea & Ignimbrita & $\begin{array}{l}\text { Estratificación } \\
\text { / Fracturas }\end{array}$ & MQ-MT \\
\hline 20 & Alero 12 & Puna Estepa 35 & $100 / 10$ & Ígnea & Rio-dacita & Diaclasas & MT-MQ \\
\hline 21 & $\begin{array}{l}\text { Alero Peńas } \\
\text { Chicas } \\
1.1 \text { (PCh 1.1) }\end{array}$ & Puna Estepa 35 & $130 / 10$ & Ígnea & Ignimbrita & $\begin{array}{l}\text { Diaclasas / } \\
\text { Fracturas }\end{array}$ & MT-MQ \\
\hline 22 & $\begin{array}{l}\text { Alero Peñas } \\
\text { Chicas } \\
1.7 \text { (PCh 1.7) }\end{array}$ & Puna Estepa 35 & $130 / 10$ & Ígnea & Ignimbrita & $\begin{array}{l}\text { Diaclasas / } \\
\text { Fracturas }\end{array}$ & MT-MQ \\
\hline 23 & $\begin{array}{l}\text { Alero } 1 \text { Punta de } \\
\text { la Peńa } 9 \text { (PP9) }\end{array}$ & Puna Estepa 35 & $130 / 10$ & Ígnea & Ignimbrita & $\begin{array}{l}\text { Diaclasas / } \\
\text { Fracturas }\end{array}$ & MT-MQ \\
\hline 24 & Alero La Gruta & Puna Estepa 35 & $500 / 12$ & $\begin{array}{l}\text { Sedimen- } \\
\text { taria }\end{array}$ & Arenisca & $\begin{array}{c}\text { Homogénea / } \\
\text { Fracturas }\end{array}$ & MQ-MT \\
\hline
\end{tabular}

Tabla 4. Ambientes identificados para cada una de las regiones analizadas.

\begin{tabular}{ccc}
\hline Región & Ambiente & Altura \\
\hline Estepa Arbustiva 42 & \\
Estagonia & Estepa Húmeda 47 & Entre 15 y $560 \mathrm{msnm}$ \\
& Monte Estepa 25 & \\
\hline Región Pampeana & Pampa Pseudoestepa 34 38 & Entre 93 y $288 \mathrm{msnm}$ \\
\hline COA & Altoandina Estepa 36 $2900 \mathrm{msnm}$ \\
\hline Sierras Centrales & Chaco Bosque 7 & \\
& Pastizal de Altura 8 & Entre 1150 y $2190 \mathrm{msnm}$ \\
\hline NOA & Prepuna Estepa 6 & \\
\hline
\end{tabular}

En cuanto al clima, la muestra analizada exhibe un rango relativamente amplio con precipitaciones anuales que oscilan entre 100 y 900 milímetros y con temperaturas medias anuales que varían entre 5 y $17^{\circ} \mathrm{C}$ (Tabla 3$)$.

Los sitios de la muestra están labrados en los tres tipos de rocas: ígneas, sedimentarias y metamórficas, siendo las primeras las que presentan más variedades (siete). Las rocas sedimentarias están representadas por dos tipos y las metamórficas solo por uno. La roca más frecuente en los casos de estudio es la ignimbrita (Tabla 3 y Fig. 3B). 


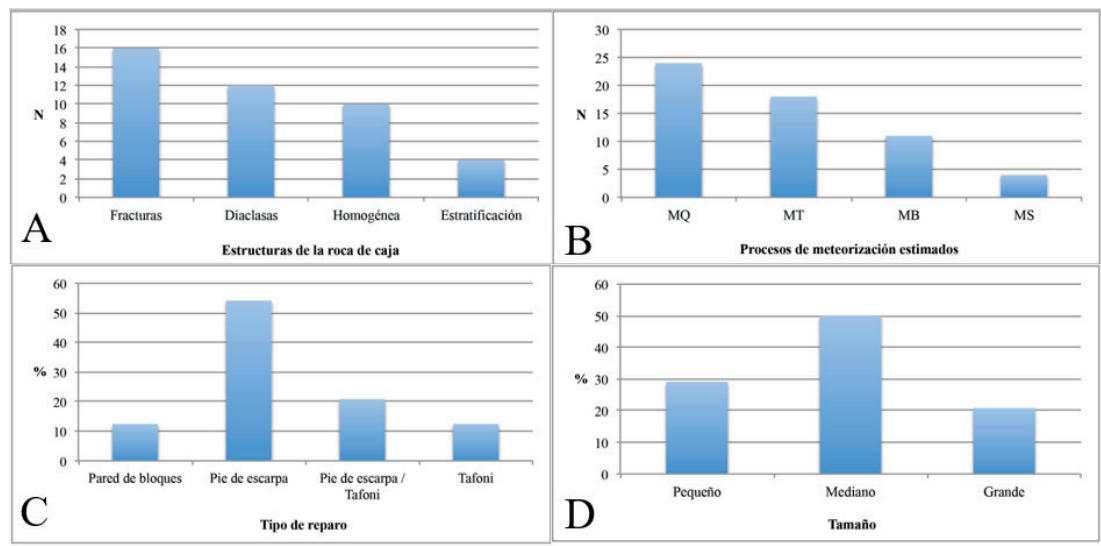

Figura 4. A. Estructuras presentes en las rocas de caja de los sitios analizados. B. Procesos de meteorización estimados en los casos de estudio. C. Tipos de reparos analizados. D. Tamaño de los reparos rocosos analizados (elaboración: D.M. Kligmann).

En la muestra analizada se observan combinaciones de los cuatro tipos de estructuras en la roca de caja de los aleros y cuevas considerados (Tabla 3). La estratificación es el único caso que no se da aislado, sino que siempre se presenta combinado con otro. Si se considera cada uno de los tipos por sí solos, se encuentra en primer lugar a las fracturas irregulares (16 casos), seguidas por las diaclasas (fracturas orientadas, 12 casos), luego por las estructuras homogéneas (10 casos) y, por último, por la estratificación (cuatro casos) (Fig. 4A).

Finalmente, y en lo que respecta a los procesos de meteorización estimados, se consideraron cuatro opciones que dan lugar a seis combinaciones (Tabla 3). Cabe destacar que ninguna de las opciones se estima que actúa aislada, sino que siempre está combinada con uno o más procesos. La única alternativa que se supone presente en todos los sitios es la «meteorización química». Le siguen la "meteorización por cambios de temperatura» (18 casos), la "biológica» (11 casos) y por «sales» (cuatro casos) (Fig. 4B).

\section{El sitio (variables 12 a 15 )}

Los sitios analizados se pueden clasificar en tres tipos de reparos en función de su origen (Tabla 5). La opción dominante es "pie de escarpa», con 13 casos, seguida por la combinación "pie de escarpa/ tafoni» (cinco casos) y luego por las variantes individuales «tafoni» $\mathrm{y}$ "pared de bloque» con tres casos cada una (Fig. 4C).

$\mathrm{El}$ ancho de los reparos rocosos de la muestra analizada oscila entre 0.8 y 55 metros, la profundidad entre 1.2 y 24 metros y el alto entre 0.5 y 9 metros, siendo el ancho la dimensión que presenta el mayor rango de variabilidad. Un dato curioso es que en el conjunto analizado no hay ningún reparo cuyo ancho se encuentre entre 15 y 22 metros, lo que evidencia un salto en las dimensiones. Lo mismo se aprecia en la profundidad, siendo que en este caso la ausencia se produce entre los 12 y los 22.5 metros (Tabla 5). Es probable que esto represente sesgos en la muestra analizada, pero de todos modos es útil comenzar a controlarlo por si se mantuviera alguna tendencia al incrementar el número de casos.

En función de las dimensiones de los sitios, se los clasificó teniendo en cuenta tres categorías (Tabla 5). La opción dominante es «mediano», con 12 casos, seguida de los sitios pequeños y, finalmente, de los grandes, que son los menos representados en la muestra (Fig. 4D). Esta primera clasificación es operativa, pero permite evaluar los tamaños más recurrentes en los reparos rocosos para luego cotejarlos con otras variables. 
Tabla 5. Morfología y dimensiones de los sitios analizados.

\begin{tabular}{|c|c|c|c|c|c|}
\hline \multirow[b]{2}{*}{$\mathrm{N}^{\circ}$} & \multirow[b]{2}{*}{$\begin{array}{l}\text { SITIO } \\
\text { (de sur a norte) }\end{array}$} & \multirow{2}{*}{$\begin{array}{c}\text { MORFOLOGÍA } \\
\begin{array}{c}\text { Tipo de cavidad / } \\
\text { reparo }\end{array}\end{array}$} & \multicolumn{3}{|c|}{ DIMENSIONES } \\
\hline & & & $\begin{array}{c}\text { Ancho / } \\
\text { profundidad / } \\
\text { alto }(\mathbf{m})\end{array}$ & Tamańo & $\begin{array}{c}\text { Relación } \\
\text { ancho / } \\
\text { profundidad }\end{array}$ \\
\hline 1 & Alero Cabeza de León 1 (CL1) & tafoni & $11 \times 4.5 \times 3$ & mediano & 2.44 \\
\hline 2 & Alero Chorrillo Malo 2 (CHM2) & pared de bloques & $9 \times 4 \times 4$ & mediano & 2.25 \\
\hline 3 & Alero El Puesto 1 (AEP-1) & pie de escarpa & $22 \times 4 \times 3.5$ & grande & 1.5 \\
\hline 4 & Cueva Maripe & pie de escarpa & $26 \times 24 \times 2$ & grande & 1.08 \\
\hline 5 & Alero El Triunfo & pie de escarpa / tafoni & $9 \times 3 \times 6$ & mediano & 3 \\
\hline 6 & Alero 4 Cañadón Torcido & pie de escarpa & $7 \times 2.3 \times 5$ & pequeño & 3.04 \\
\hline 7 & Alero 2 Punta Pórfido (A2 PP) & tafoni & $9.5 \times 4.5 \times 4$ & mediano & 2.11 \\
\hline 8 & Cueva Amalia Sitio 2 & pared de bloques & $0.8 \times 4 \times 2$ & pequeño & 0.2 \\
\hline 9 & Cueva Tixi & pie de escarpa & $10 \times 8 \times 1.8$ & mediano & 1.25 \\
\hline 10 & Abrigo La Tinta & pie de escarpa & $5 \times 4 \times 3$ & pequeño & 1.25 \\
\hline 11 & Alero Agua de la Cueva SN & pie de escarpa & $55 \times 6 \times 2$ & grande & 9.17 \\
\hline 12 & Alero Dupuy & pie de escarpa & $8 \times 5 \times 2.5$ & pequeño & 1.6 \\
\hline 13 & Alero La Angostura 1 & pie de escarpa & $28 \times 5 \times 9$ & grande & 5.6 \\
\hline 14 & Gruta de Intihuasi & pie de escarpa / tafoni & $27 \times 22.5 \times 3.7$ & grande & 1.2 \\
\hline 15 & Alero Los Morteros & pie de escarpa & $13 \times 4 \times 3$ & mediano & 3.25 \\
\hline 16 & Alero La Enramada 3 & pie de escarpa & $10 \times 3 \times 2.5$ & mediano & 3.33 \\
\hline 17 & Alero Arroyo El Gaucho 1 & pie de escarpa & $9 \times 4.6 \times 2.4$ & mediano & 1.96 \\
\hline 18 & Cueva Quebrada del Real & pie de escarpa & $3.5 \times 10 \times 2$ & pequeño & 0.35 \\
\hline 19 & Cueva Abra del Toro & pie de escarpa / tafoni & $12 \times 12 \times 5$ & mediano & 1 \\
\hline 20 & Alero 12 & pie de escarpa & $9 \times 5 \times 2.5$ & mediano & 1.8 \\
\hline 21 & Alero Peñas Chicas 1.1 (PCh 1.1) & pie de escarpa / tafoni & $15 \times 3 \times 6$ & mediano & 5 \\
\hline 22 & Alero Peñas Chicas 1.7 (PCh 1.7) & pie de escarpa / tafoni & $15 \times 1.6 \times 6$ & mediano & 9.38 \\
\hline 23 & Alero 1 Punta de la Peńa 9 (PP9) & pared de bloques & $3 \times 2 \times 0.5$ & pequeño & 1.5 \\
\hline 24 & Alero La Gruta & tafoni & $3 \times 1.2 \times 2.5$ & pequeño & 2.5 \\
\hline
\end{tabular}


Si se vincula el tamaño de los reparos con la litología, se puede observar que los medianos, al conformar el tamańo dominante de la muestra, son los que presentan mayor variabilidad de rocas (siete), seguidos por los pequeños (cinco) y, finalmente, por los grandes (cuatro). Estos últimos están labrados en rocas ígneas (andesitas e ignimbritas), sedimentarias (areniscas) y metamórficas (esquistos), siendo las ignimbritas y las areniscas las únicas rocas que presentan reparos de los tres tamańos seleccionados para el análisis.

De los 24 casos considerados, 18 han sido categorizados como aleros y seis como cuevas, de acuerdo con sus nombres originales. Sin embargo, si se tiene en cuenta la relación ancho/profundidad aquí considerada, solo dos casos arrojan valores menores a 1 ( 0.2 y 0.35$)$, lo que se toma como un posible parámetro para definirlos como cuevas (Tabla 5). Las otras cuatro cuevas de la muestra, definidas como tales a priori, presentan valores que oscilan entre 1 y 1.25 . Sin embargo, ello se ajusta bastante bien al esquema clasificatorio propuesto, con la idea de que al ser un continuum existe una zona de transición entre los dos extremos dados por las categorías alero y cueva. Eso explica también que dos sitios con el mismo valor (1.25) hayan sido clasificados de manera diferente por los arqueólogos que los excavaron: uno como alero (abrigo La Tinta) y el otro como cueva (cueva Tixi). Merece asimismo destacarse la enorme variabilidad de morfologías que existe en los aleros, con una proporción ancho/profundidad que oscila entre 1.25 y 9.38 .

\section{Su relleno (variables 16 a 21 )}

Los rellenos analizados presentan entre 0.30 y más de 10 metros de profundidad y corresponden a la excavación del total o de una parte de la potencia sedimentaria de los sitios (Tabla 6). Al respecto, puede decirse que los sitios con los rellenos más potentes excavados al presente no necesariamente son los más grandes ni tampoco los más antiguos. La excepción a estos argumentos la constituye la Gruta de Intihuasi, un sitio excepcional por su tamaño. Se trata quizás de la cueva más grande de la Argentina hasta ahora reportada, superando los 10 metros de relleno sedimentario pero con solo 2 metros correspondientes al Holoceno. Este espesor es similar al de otros rellenos presentes en cuevas y que son atribuibles al Holoceno.

En aleros y cuevas el relleno suele estar conformado por materiales tanto endógenos como exógenos. Para el análisis de la proporción relativa del material endógeno se identificaron tres opciones, dominando la alternativa «elevado» en este primer estudio (Tabla 6 y Fig. 5A). Esto significa que la gravedad fue el principal agente de aporte por caída de clastos y bloques de techos y paredes de los reparos, hecho posible por la meteorización previa de la roca de caja. En los casos de rocas resistentes a la meteorización, esto representaría mucho tiempo transcurrido en poca potencia sedimentaria mientras que, si se trata de rocas poco resistentes, habrá menor cantidad de tiempo representado en un depósito equivalente bajo las mismas condiciones de meteorización.

Entre los agentes involucrados en el aporte de material exógeno se puede apreciar el viento, el agua y la gravedad en diferentes combinaciones, siendo el viento el agente dominante y actuante en todos los sitios analizados (Tabla 6 y Fig. 5B). El aporte relativo de este último se halla muy relacionado con la orientación del frente del alero o de la boca de la cueva.

Solo algo más de la mitad de los reparos analizados reportan rasgos pedogenéticos, predominando la humificación (Tabla 6 y Fig. 5C). Esta variable está vinculada con la posibilidad de desarrollo de vegetación. Al depender tanto de las condiciones de humedad como de la radiación solar, la humificación suele restringirse a los aleros o a la parte frontal de las cuevas. 
Tabla 6. Características de los rellenos analizados y cronología.

\begin{tabular}{|c|c|c|c|c|c|c|c|}
\hline \multirow[b]{2}{*}{$\mathrm{N}^{\circ}$} & \multirow[b]{2}{*}{$\begin{array}{l}\text { SITIO } \\
\text { (de sur a norte) }\end{array}$} & \multicolumn{6}{|c|}{ CARACTERÍSTICAS DEL RELLENO } \\
\hline & & $\begin{array}{l}\text { Profundidad } \\
\text { máxima del } \\
\text { relleno }(\mathrm{cm})\end{array}$ & $\begin{array}{c}\text { Proporción } \\
\text { relativa del } \\
\text { material } \\
\text { endógeno }\end{array}$ & $\begin{array}{l}\text { Agentes invo- } \\
\text { lucrados en el } \\
\text { aporte de mate- } \\
\text { rial exógeno }\end{array}$ & $\begin{array}{c}\text { Rasgos } \\
\text { pedogenéticos }\end{array}$ & $\begin{array}{c}\text { Restos } \\
\text { orgánicos } \\
\text { preservados }\end{array}$ & $\begin{array}{c}\text { Edad } \\
\text { máxima } \\
\text { obtenida }\end{array}$ \\
\hline 1 & $\begin{array}{l}\text { Alero Cabeza de León } \\
1 \text { (CL1) }\end{array}$ & 60 & elevado & Viento & radículas & C-H-V-M & $1100 \mathrm{AP}$ \\
\hline 2 & $\begin{array}{l}\text { Alero Chorrillo Malo } 2 \\
\text { (CHM2) }\end{array}$ & 170 & elevado & Viento / Agua & humificación & $\mathrm{C}-\mathrm{H}$ & $9700 \mathrm{AP}$ \\
\hline 3 & $\begin{array}{l}\text { Alero El Puesto } 1 \\
\text { (AEP-1) }\end{array}$ & 100 & elevado & Viento & $\begin{array}{c}\text { humificación/ } \\
\text { Bt }\end{array}$ & $\mathrm{C}-\mathrm{H}$ & $12,890 \mathrm{AP}$ \\
\hline 4 & Cueva Maripe & 200 & elevado & Viento & humificación & $\mathrm{C}-\mathrm{H}$ & $9500 \mathrm{AP}$ \\
\hline 5 & Alero El Triunfo & 40 & elevado & Viento & no & $\mathrm{C}$ & $2430 \mathrm{AP}$ \\
\hline 6 & $\begin{array}{l}\text { Alero } 4 \text { Cańadón } \\
\text { Torcido }\end{array}$ & 45 & elevado & Viento & radículas & C-H-V & $2760 \mathrm{AP}$ \\
\hline 7 & $\begin{array}{l}\text { Alero } 2 \text { Punta Pórfido } \\
\text { (A2 PP) }\end{array}$ & 130 & elevado & Viento & radículas & C-H-V-P & $6600 \mathrm{AP}$ \\
\hline 8 & Cueva Amalia Sitio 2 & 230 & bajo & $\begin{array}{l}\text { Viento / Agua / } \\
\text { Gravedad }\end{array}$ & no & $\mathrm{C}$ & $10,700 \mathrm{AP}$ \\
\hline 9 & Cueva Tixi & 90 & bajo & Viento / Agua & humificación & $\mathrm{C}-\mathrm{H}$ & $10,300 \mathrm{AP}$ \\
\hline 10 & Abrigo La Tinta & $>$ a 65 & medio & Viento / Agua & humificación & $\mathrm{C}$ & $10,400 \mathrm{AP}$ \\
\hline 11 & $\begin{array}{l}\text { Alero Agua de la } \\
\text { Cueva SN }\end{array}$ & 250 & medio & $\begin{array}{l}\text { Viento / Agua / } \\
\text { Gravedad }\end{array}$ & no & C-H-M & $9400 \mathrm{AP}$ \\
\hline 12 & Alero Dupuy & 90 & medio & Viento & humificación & C-H & $4598 \mathrm{AP}$ \\
\hline 13 & Alero La Angostura 1 & 35 & elevado & Viento & humificación & $\mathrm{C}-\mathrm{H}$ & $1140 \mathrm{AP}$ \\
\hline 14 & Gruta de Intihuasi & > a 1000 & medio & Viento / Agua & no & $\mathrm{C}-\mathrm{H}-\mathrm{V}$ & 8068 AP \\
\hline 15 & Alero Los Morteros & 50 & bajo & Viento & humificación & $\mathrm{C}-\mathrm{H}$ & $3144 \mathrm{AP}$ \\
\hline 16 & Alero La Enramada 3 & 80 & bajo & Viento & humificación & $\mathrm{C}-\mathrm{H}$ & $10,690 \mathrm{AP}$ \\
\hline 17 & $\begin{array}{l}\text { Alero Arroyo } \\
\text { El Gaucho } 1\end{array}$ & 115 & bajo & Viento & humificación & $\mathrm{C}-\mathrm{H}-\mathrm{V}$ & $7160 \mathrm{AP}$ \\
\hline 18 & $\begin{array}{l}\text { Cueva Quebrada del } \\
\text { Real }\end{array}$ & 130 & medio & Viento & no & C-H-V & $7360 \mathrm{AP}$ \\
\hline 19 & Cueva Abra del Toro & 180 & bajo & Viento / Agua & humificación & $\mathrm{C}-\mathrm{H}$ & $4582 \mathrm{AP}$ \\
\hline 20 & Alero 12 & 80 & bajo & Viento & no & C-H & $590 \mathrm{AP}$ \\
\hline 21 & $\begin{array}{l}\text { Alero Peñas Chicas } \\
1.1 \text { (PCh 1.1) }\end{array}$ & 80 & medio & Viento & no & C-H-T-P & $3660 \mathrm{AP}$ \\
\hline 22 & $\begin{array}{l}\text { Alero Peñas Chicas } \\
1.7 \text { (PCh 1.7) }\end{array}$ & 94 & medio & Viento & no & C-H-M-P & $4145 \mathrm{AP}$ \\
\hline 23 & $\begin{array}{l}\text { Alero } 1 \text { Punta de la } \\
\text { Peńa } 9 \text { (PP9) }\end{array}$ & > a 30 & medio & Viento & no & $\begin{array}{l}\text { C-H-M- } \\
\text { P-T }\end{array}$ & $1479 \mathrm{AP}$ \\
\hline 24 & Alero La Gruta & 30 & elevado & Viento & no & $\mathrm{C}-\mathrm{H}$ & $224 \mathrm{AP}$ \\
\hline
\end{tabular}



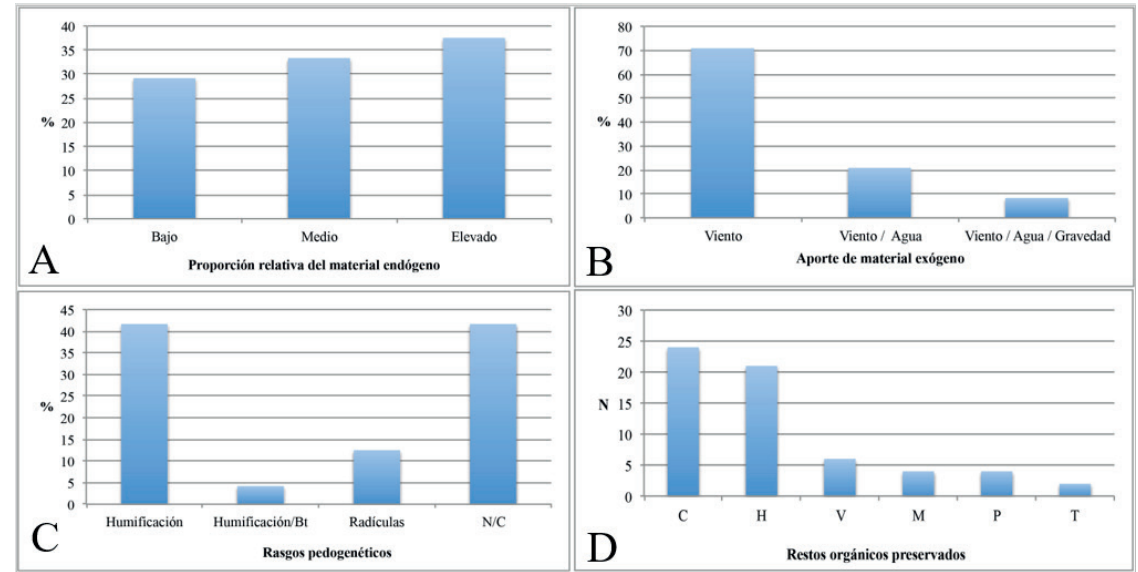

Figura 5. A. Proporción relativa del material endógeno en los casos de estudio. B. Agentes involucrados en el aporte de material exógeno en los casos de estudio. C. Rasgos pedogenéticos identificados en los casos de estudio. D. Restos orgánicos preservados en los rellenos analizados (elaboración: D.M. Kligmann).

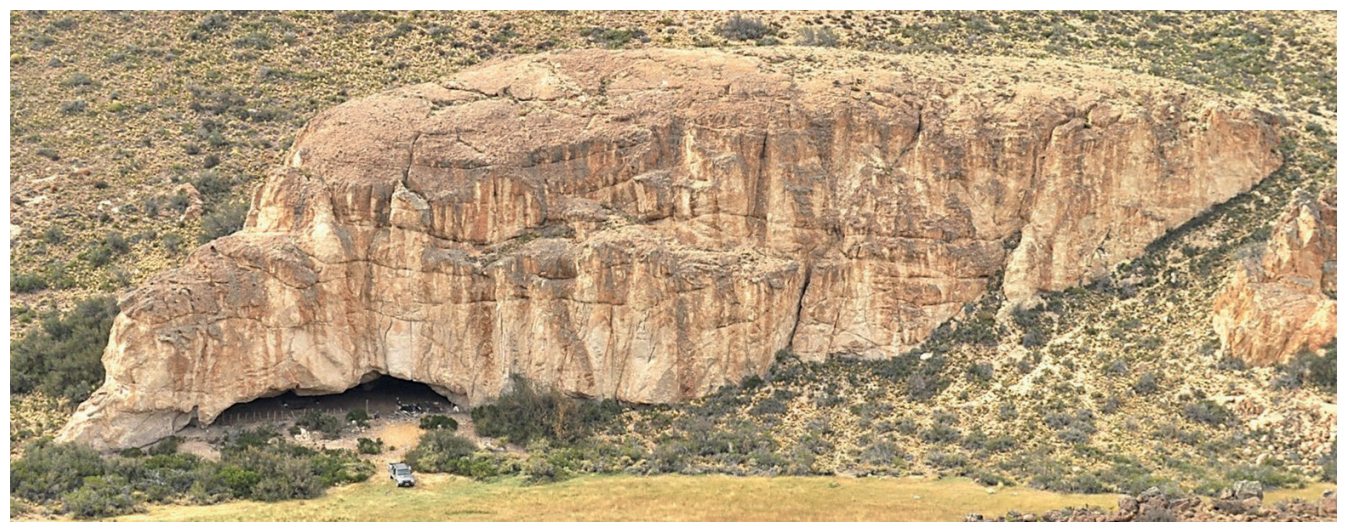

Figura 6. Cueva Maripe, nótese la escotadura basal en la roca a lo largo del afloramiento que ocurre en el contacto con el sustrato (foto: S. Carreño).

De los seis tipos de restos orgánicos preservados surgen nueve combinaciones diferentes (Tabla 6). El carbón es el único elemento identificado en todos los sitios analizados, ya sea que se encuentre solo o combinado con otros. En segundo lugar, le siguen los restos óseos, presentes en 21 sitios. Su persistencia tendría que ver con los parámetros geoquímicos (v.g. pH y óxido-reducción) que predominan en los ambientes de aleros y cuevas, ubicados en un rango que suele favorecer su preservación (valores de $\mathrm{pH}$ entre 6 y 10, ya sea asociados con sedimentos bien drenados o saturados de agua [Retallak 1990]), aunque se registren también excepciones. Las valvas están presentes en seis de los sitios analizados, los restos vegetales y las plumas en cuatro y los textiles solo en dos (Fig. 5D). Si bien los contenidos de los rellenos se vinculan con las posibilidades de preservación de los reparos rocosos, también están condicionados por los tipos de materiales efectivamente introducidos en ellos según la función de los sitios y su contexto cultural.

Finalmente, y en lo que respecta a la cronología de los casos de estudio, el rango observado oscila entre los años radiocarbónicos 224 y 12,890 AP (Tabla 6). Los cinco fechados más antiguos de la muestra analizada se dan tanto en aleros como en cuevas, independientemente de su tamaño. 


\section{Consideraciones generales y algunos patrones observados a partir del análisis comparativo de los casos de estudio}

\subsection{Influencia del contexto geoambiental en la generación de reparos y rellenos}

Varios mecanismos contribuyen a la retroalimentación positiva que conduce al crecimiento del tamaño de escotaduras y cavidades, pero el más comúnmente citado es una mayor concentración de humedad o una especial susceptibilidad de la roca a la misma (Pope et al. 1995; Turkington y Phillips 2004). El agua favorece en gran medida los procesos de meteorización, principalmente química, pero también física ( $v$.g. crecimiento de cristales de hielo y de sales), por lo que se considera el principal agente de generación de escotaduras y cavidades en los casos analizados. En relación con este parámetro, las precipitaciones de los sitios estudiados oscilan entre 100 y 900 milímetros; es decir, no se identifican regiones muy húmedas. Por otro lado, las temperaturas medias oscilan entre 5 y $17^{\circ} \mathrm{C}$, no obstante, se destacan las amplitudes térmicas que, por lo general, resultan de 10 a $18{ }^{\circ} \mathrm{C}$ o más. En todas las áreas analizadas la temperatura llega a menos de $0{ }^{\circ} \mathrm{C}$ en algún período del año, lo que combinado con elevadas amplitudes térmicas favorece los procesos de meteorización térmica (termoclastismo y/o crioclastismo). En los aleros ubicados en la costa se suma el efecto de las sales aportadas por la bruma marina, que intensifican procesos de meteorización física como el haloclastismo. Los procesos de meteorización biológica también poseen un impacto, que aún debe evaluarse con mayor detalle, a partir de la acción de líquenes y de raíces (arbustos y árboles principalmente) que ocurre tanto en ambientes semiáridos como húmedos.

La relativa resistencia de una roca a la meteorización depende de varios factores. Uno de ellos es su litología, dado que los minerales componentes de una roca poseen diferente sensibilidad a este proceso. La velocidad de meteorización de un mineral se relaciona con la estabilidad relativa que este posee en superficie, referida a la serie de Goldich (1938), en la que uno de los más resistentes es el cuarzo. Debe tenerse en cuenta, además, que un mismo tipo de roca varía en su mineralogía. En este sentido, hace falta aún conocer con mayor grado de detalle la mineralogía de las rocas involucradas para un estudio comparativo, dado que casi en ningún sitio hay estudios de detalle de la roca de caja que involucren análisis texturales y composicionales. No obstante, se parte del conocimiento de que rocas cuarzosas como las ortocuarcitas, por ejemplo, se hallan entre las más resistentes a la meteorización en el rango de las condiciones ambientales que se contemplan. Respecto a la estructura, rocas masivas y homogéneas serán más resistentes que aquéllas que presenten fracturas irregulares, diaclasas o planos de estratificación sobre los cuales pueda comenzar a actuar diferencialmente la meteorización. Finalmente, en términos climáticos, la meteorización física tiende a dominar en ambientes áridos y la química en ambientes húmedos, procesos a los que las rocas también responderán de manera diferente de acuerdo con su mineralogía y estructura. Es decir, el clima puede acelerar o retardar la meteorización según la temperatura y la humedad, por lo que un mismo tipo de roca va a meteorizarse a ritmos diferentes según el ambiente donde esté ubicada.

La velocidad de meteorización de las cavidades se vincula con su tasa de aporte al relleno. Una meteorización muy lenta generada en rocas relativamente resistentes permitiría alcanzar una cronología muy antigua en un relleno de poco desarrollo (siempre y cuando haya poca intervención de aportes exógenos, incluyendo los antrópicos). En otras ocasiones, existen períodos de estabilidad prolongados que generan hiatos temporales en los rellenos por cese de aporte sedimentario. Bajo condiciones de estabilidad podrían observarse procesos de pedogénesis. Si estos últimos no son viables, pueden evidenciarse otros procesos diagenéticos que indiquen un período de estabilidad prolongado, entre ellos la oxidación, disolución o cementación, dependientes de la litología del relleno y de las condiciones microambientales (Courty et al. 1989; Farrand 1993; Farrand 2001b). No resulta sencillo modelar los procesos de meteorización y generación de rellenos en un alero si no se cuenta con un número importante de casos estudiados en cada localidad. No obstante, este estudio inicial muestra algunos avances desde un abordaje a escala macrorregional. 
En los casos analizados, las litologías han resultado muy variadas: pegmatitas, granitos, riolitas, dacitas, andesitas, ignimbritas, areniscas, ortocuarcitas y esquistos. Los rellenos de cavidades desarrolladas en ortocuarcitas (Buenos Aires) y granitos (Córdoba) han alcanzado edades de ca. 10,000 ańos con los menores espesores relativos (con algunas excepciones, como la Cueva Amalia Sitio 2). Si bien, como se ha señalado, este no es el único parámetro para tener en cuenta, resulta coherente con la lenta meteorización esperable en este tipo de rocas que poseen minerales resistentes (Tabla 3). La estratigrafía en algunas de estas secuencias, ubicadas en regiones templado húmedas, evidencia una pedogénesis continuada indicada por procesos de humificación (Tabla 6). Ello es consistente con tasas de sedimentación muy bajas, por aporte principalmente endógeno. Si la estabilidad resulta predominante, se puede desarrollar un perfil de suelo en algunos sitios que diferencie varios horizontes, incluido un horizonte Bt. Esto es lo que ocurre en el caso del Alero El Puesto 1 (AEP-1) (Santa Cruz), donde también se alcanza una elevada antigüedad (12,890 años $\mathrm{AP})$ en un relleno de solo un metro.

En algunas cavidades generadas en ignimbritas se observa cierta proporcionalidad entre edades y rellenos. Aleros en esta roca en la costa norte de Santa Cruz (Alero El Triunfo y Alero 4 Cańadón Torcido) poseen edades de unos 2430 y 2760 en secuencias de 40 a 45 centímetros de profundidad, mientras que en Catamarca los aleros Peñas Chicas (PCh) 1.7 y Punta de la Peña 9 (PP9) poseen edades de 4145 años y de 1479 años en secuencias de 94 y 30 centímetros, respectivamente. En ambas provincias los aleros se desarrollan bajo condiciones de aridez y no se han observado procesos de pedogénesis en sus secuencias. Se podría considerar que tal proporcionalidad entre edades y rellenos apuntaría a tasas relativamente constantes de acumulación en el tiempo. Sin embargo, por lo general no ocurre de esa forma y los controles temporales proporcionados por los fechados suelen demostrarlo. Es frecuente que existan variaciones en las tasas de sedimentación, a veces importantes, por diversas razones, incluyendo las provocadas por intervenciones antrópicas (v.g. procesos de acumulación o de remoción vinculados con la intensidad de la ocupación, tipo de actividades y tasa de descarte). En Cueva Maripe (Santa Cruz), por ejemplo, desarrollada asimismo sobre ignimbritas, numerosas edades radiocarbónicas que alcanzan los 9500 años AP evidencian pulsos discontinuos de depositación en la acumulación del relleno (Mosquera 2015).

En relación con la estructura, la presencia de fracturas irregulares y, en particular, de diaclasas, colabora mucho en la desagregación de la roca. Las diaclasas, fracturas y esquistosidad marcada que se observan, por ejemplo, en Agua de la Cueva sector norte, facilitan mucho su desagregación. Este último proceso, sumado al aporte alóctono, ha generado el mayor espesor del relleno holoceno registrado en los aleros bajo estudio ( 2.5 metros). La estructura también puede condicionar en algunos casos la morfología de los aleros. Esto ocurre en los casos de Tandilia (Martínez 2007), donde la formación de aleros y cuevas involucra procesos de meteorización a partir de planos de diaclasas y de estratificación que ejercen claro control sobre las morfologías resultantes de aspecto cuadrangular (Fig. 1C).

\subsection{Morfología y tipo de reparos rocosos: su evolución}

De acuerdo con Turkington y Phillips (2004), la similitud en las formas que las escotaduras y cavidades adquieren al evolucionar indica un proceso de auto organización del sistema de meteorización que se alcanzaría en forma independiente del agente en particular. Es decir, se observa una convergencia en sus morfologías más allá de los procesos de meteorización involucrados, que les otorga una apariencia cóncava o esferoidal similar. No obstante, esta puede ser modificada de existir un control estructural importante como ocurre en los casos de Tandilia. Respecto al grado de concavidad, se podría volver a considerar un continuum en los reparos rocosos, desde un alero plano (pared casi vertical) hasta una cueva (concavidad de profundidad variable).

Más allá de su morfología, el proceso principal que les da origen (y su contexto de formación) permite separar los reparos rocosos en diferentes tipos. En los casos analizados, y en función de la 
clasificación de Mentzer (2017), se observan básicamente tres subtipos: 1) de pie de escarpa, 2) tafoni y 3) de abrasión y arrastre (variedad pared de bloque).

1) La mayoría de los reparos se ha formado en la base de farallones o afloramientos rocosos (pie de escarpa) donde toman contacto con un sustrato de grano fino que retiene humedad, sean sedimentos del talud o de la base del afloramiento (Fig. 6). Es destacable que este fenómeno se registra en todas las regiones climáticas y litologías, patrón que ha sido notado también por Martínez (2007) en su estudio comparativo intrarregional de reparos rocosos en Tandilia. La meteorización vehiculizada por la humedad que, aunque sea baja, siempre es mayor en ese contacto (McDonald y Twidale 2011), resulta entonces el factor clave para el desarrollo de aleros y cuevas por mecanismos físico-químicos y biológicos. Turkington y Phillips (2004) señalan que variaciones iniciales altamente localizadas (incluso variaciones menores) en la resistencia a la intemperie, como pueden ser las características microtopográficas, los impactos bióticos o las fracturas, tienden a amplificarse con el tiempo en un proceso de divergencia inestable. El retroceso, rebajamiento o escotadura basal puede constituir un plano inclinado en algunos casos (Aleros Peńas Chicas 1.1 y La Angostura 1, Fig. 7A), una cavidad incipiente (Alero 4 Cañadón Torcido, Alero Dupuy, Alero Los Morteros, Alero 12 y Alero Cabeza de León 1 (CL1), Fig. 7B) o una cavidad profunda (Cueva Maripe, Fig. 6), ilustrando aquel continuum mencionado. La morfología de esta escotadura tiende a ser alargada longitudinalmente, pudiendo en ocasiones alcanzar decenas de metros (Aleros Agua de la Cueva sector norte y La Angostura 1, Fig. 7A).

2) Las cavidades denominadas tafoni, en cambio, presentan desarrollo diverso a diferentes alturas del frente rocoso. Su forma es circular u ovalada (Alero 2 Punta Pórfido o A2 PP, La Gruta, El Triunfo y Alero CL1, Fig. 7B). Se ha observado que la mayoría de ellos permanecen sin relleno o con apenas un detrito temporario aún en aquellos de tamaños grandes (Fig. 1B parte superior). Este relleno se registra particularmente en los reparos que han sido alcanzados por el talud de la escarpa (Alero CL1, A2 PP) o que han tomado contacto con la superficie del terreno (La Gruta, El Triunfo, Intihuasi, Fig. 7C). Esto último ocurre al evolucionar un tafone cerca de la base del afloramiento. Tal contacto parece permitirles conservar su relleno, que ya no escapa con facilidad como ocurre cuando se halla ubicado en otras posiciones (Favier Dubois et al. 2020). En algunos casos, dos o más tafoni se unen para formar una cavidad mayor (v.g. A2 PP). Es posible que la Gruta de Intihuasi se haya desarrollado a partir de este proceso de coalescencia, cuya suma terminó constituyendo un enorme tafone (Ojeda y Pedersen 2019) (Fig. 7C).

3) En el caso de los bloques rocosos, sean estos caídos de una escarpa (Alero 1 PP9) o arrastrados por un glaciar (Alero Chorrillo Malo 2 o CHM2), las paredes originales de los mismos han funcionado como aleros y su posterior meteorización los ha ido transformando en un reparo algo más profundo. Esto es evidente en el Alero CHM2, donde la mitad inferior de la pared que forma el alero presenta una concavidad que no se hallaría en la pared original del bloque, siendo producto de la meteorización diferencial una vez que este se depositó por acarreo glacial (Pleistoceno Tardío). En este alero se realizó un estudio sobre su paulatina colmatación, así como sobre la caída de bloques de la pared, que ayudó a explicar los cambios observados en el uso del espacio disponible a lo largo del tiempo (Mehl y Franco 2009). En el caso particular de la Cueva Amalia Sitio 2, fue el dislocamiento basal de bloques del afloramiento rocoso lo que parece haber generado la cavidad angosta y profunda entre sus paredes.

La evolución de los reparos rocosos, dependiendo del caso y su estabilidad, puede llevarlos a colmatarse, erosionarse o colapsar. Borrero et al. (2007) destacan la importancia de los procesos de colapso de aleros en una región y cómo esto produce un sesgo para los estudios arqueológicos haciendo necesario prever su posible existencia en los diseńos de investigación. Los autores refieren el caso de un sitio a cielo abierto junto a una formación rocosa de arenisca, descubierto mediante sondeos de pala sistemáticos (sitio Cerro León 3 o CL3, Santa Cruz), donde la excavación permitió detectar que se trataba de un alero colapsado (Borrero et al. 2007: 136). Ello apunta a que los 


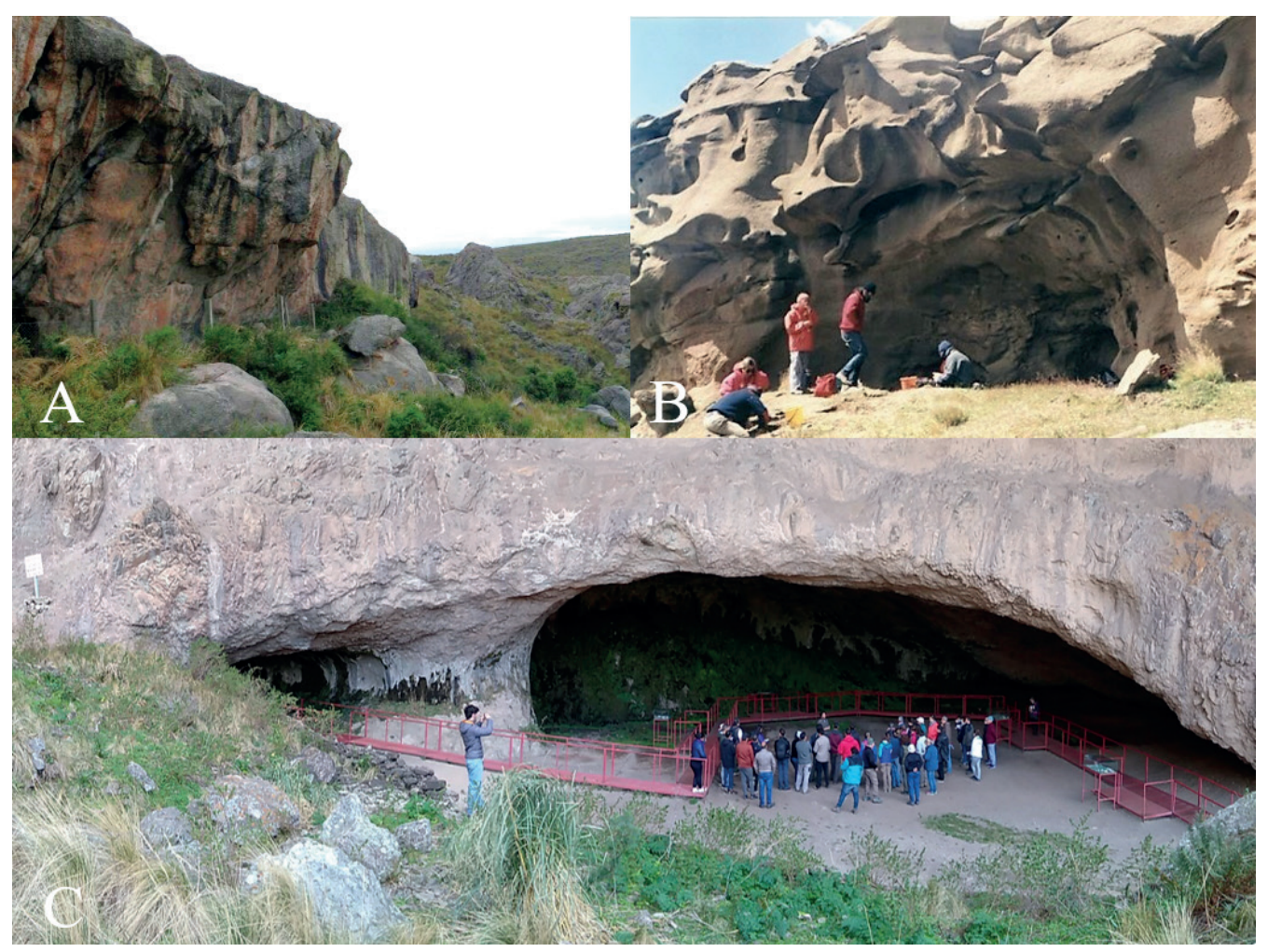

Figura 7. A. Alero La Angostura 1, escotadura en forma de plano inclinado (foto: M. Carrera Aizpitarte). B. Alero Cabeza de León, tafone irregular y poco profundo 1 (foto: C.M. Favier Dubois). C. Cueva de Intihuasi, tafone de enorme desarrollo (foto: D. Storchi Lobos).

aleros y cuevas más antiguos o los que hayan evolucionado más rápidamente hacia el colapso pueden hacerse invisibles junto a la evidencia cultural que contienen. Los procesos de colmatación, por otra parte, terminan con el uso habitable de un espacio (a excepción de que este sea reactivado) y pueden ocultar aleros y cuevas una vez que el relleno ha alcanzado su tope. Entre los casos estudiados, el Alero 1 PP9 y el Alero PCh1.7 se hallan en un proceso avanzado de colmatación, en ambos casos por aporte exógeno de origen eólico.

El aspecto de los reparos cambia con el tiempo lo que puede condicionar negativa o positivamente su valoración actual respecto al uso que pudo haber tenido en el pasado, es por ello que su estado presente no resulta un indicador fiable (Straus 1990). Una vez que los aleros y cuevas se hallan colapsados o completamente colmatados y ya no resultan visibles, los testeos con pala y otras técnicas prospectivas pueden formar parte de una metodología geoarqueológica orientada a su detección. Asimismo, algunos rasgos observados en los frentes de fractura de afloramientos rocosos (v.g. grado de meteorización, pulimento eólico, desarrollo de barnices y abundancia de líquenes) permiten separar eventos de caída de bloques en forma relativa (Pereyra y Guráieb 1998). Ello posee el potencial de indicar desprendimientos rocosos relativamente recientes que pudieran haber conformado aleros o sellado cuevas.

\subsection{Los rellenos: características, preservación y potencial cronología}

Los espesores de los rellenos relevados van de unos 0.3 metros a más de 10 metros, variación que puede relacionarse con la antigüedad del alero o cueva, su velocidad de descomposición y el aporte 
de material alóctono, entre otros factores. En principio, es esperable que las rocas más resistentes a la meteorización, es decir que posean minerales más estables y estructuras más homogéneas, sean las de evolución más lenta y con aporte autóctono más pausado. El aporte alóctono podrá variar por otras causas vinculadas al paisaje circundante y la dinámica geomorfológica en cada localidad, además de la acción faunística y antrópica.

Los procesos de pedogénesis han sido, por lo general, importantes en los rellenos, en especial en los de los aleros, dado que al hallarse más expuestos a la luz solar la vegetación puede colonizar su superficie (Farrand 2001a), tal circunstancia se ve favorecida por la humedad. Estos procesos pedogenéticos son a veces fácilmente reconocidos en la estratigrafía, pero otras veces no. El más frecuente es la humificación, que produce una melanización (oscurecimiento) del sedimento por la incorporación de materia orgánica (humus). Si predominan bajas tasas de sedimentación, este proceso se puede extender a lo largo de toda la secuencia, generando un suelo de tipo acumulativo (v.g. horizonte A cumúlico) como se ha observado en los rellenos de aleros en Santa Cruz (CHM2) y Córdoba (Aleros Los Morteros, La Enramada 3 y El Gaucho 1). Estos procesos se dan mejor en zonas relativamente húmedas (los casos mencionados poseen entre 650 y 800 milímetros de precipitaciones) y se encuentran sostenidos en el tiempo por tasas de acumulación muy bajas y relativamente constantes, a veces facilitadas por los tipos de rocas de caja (dacita y granito en los casos de Santa Cruz y Córdoba). Tasas muy bajas pueden darse en otros contextos, pero sin que exista señal pedogenética por cuestiones climáticas (aridez) o microambientales (interior de una cueva).

En algunos casos, la sedimentación puede verse muy incrementada por elevadas tasas de aporte exógeno, como ocurre en el caso de la Cueva Abra del Toro (Catamarca) donde tres cuartas partes de la estratigrafía del alero corresponden a cenizas volcánicas, vinculadas con la gran erupción del complejo volcánico Cerro Blanco (Fernández-Turiel et al. 2019). Este aporte exógeno fue facilitado por la dirección del viento en relación con la boca de la cueva (Carbonelli et al. 2019). Otro caso donde se observa un importante aporte de material exógeno piroclástico es el Alero 12 (Catamarca). Allí, posiblemente en función de este aporte, se registra la edad más reciente en relación al espesor sedimentario que cubre al material datado (590 años AP a 40 centímetros de profundidad) (Kligmann 2009). En este análisis de la sedimentación también tienen un papel importante los procesos posdepositacionales ocurridos en el relleno que, si bien no son desarrollados en esta primera contribución, serán considerados en los futuros estudios.

La presencia de bloques de diversos tamaños en el relleno de los aleros contribuye a su colmatación. Paralelamente, y de acuerdo con el tamaño del bloque, dicha presencia genera cambios en el volumen y forma del espacio utilizable, así como en las condiciones de depositación en el reparo. Estos cambios espaciales hacen que un alero pueda ser utilizado de distintas maneras a lo largo del tiempo (como se analizó en el caso de CHM2, Mehl y Franco 2009). Finalmente, la caída de bloques puede terminar de colmatar el espacio y/o acabar con el reparo que generaba y ocultarlo (el caso de CL3 en Borrero et al. 2007).

Con respecto a la preservación de materiales de origen orgánico en los rellenos, esta ha dependido en parte de la velocidad de sepultamiento (v.g. tasa de sedimentación) pero también de las condiciones de humedad y variables geoquímicas. La preservación ósea parece buena en la mayoría de los casos y, en algunos sitios, incluso se han preservado elementos delicados (plumas, pelos, restos vegetales, textiles), hecho favorecido por la aridez (v.g. Alero PCh 1.7 y Alero 1 de PP9 con 130 milímetros de precipitaciones) y/o la presencia de sales solubles (cloruros y sulfatos de sodio) en estratigrafía (A2 PP, Favier Dubois et al. 2020). Asimismo, la dinámica antrópica y biológica (v.g. pisoteo, remoción) debió facilitar la incorporación de huesos y otros materiales al sustrato, aún en los casos en los que la sedimentación haya sido muy lenta, colaborando con su preservación.

En lo que respecta a las condiciones geoquímicas, para el caso de los carbones es conocido su potencial de preservación bajo casi cualquier condición de $\mathrm{pH}$ y óxido-reducción (Retallak 1990), pero el caso de los huesos es diferente. Al parecer, estas condiciones han sido en general 
favorables para la preservación ósea (tanto la fracción mineral como orgánica) en las distintas regiones (Tabla 6). No obstante, hay pocos datos de valores de $\mathrm{pH}$ para los aleros y cuevas referidos. En el caso de Tandilia estos resultaron, por lo general, muy bajos (oscilan en varios sitios entre 3 y 5) y solo se han preservado restos óseos en Cueva Tixi, donde los valores estuvieron entre 7 y 8 (Martínez et al. 2013: 27). Otro caso donde fueron medidos lo constituye el Alero 12 (Catamarca), sitio en el cual se halló un conjunto de miles de restos óseos de microvertebrados preservados en una unidad estratigráfica con valores de $\mathrm{pH}$ de entre 7.3 y 8 (Kligmann 2009). Estos resultados han sido mencionados como ideales para la preservación de restos óseos por Linse (1992). Condiciones adecuadas también fueron registradas en la estratigrafía del A2 PP, donde el pH fluctuó entre 6.2 y 8 (Favier Dubois et al. 2020).

La buena preservación de carbones, y en muchos casos de huesos, en los sitios analizados (ver Fig. 5D y Tabla 6), ha permitido los controles cronológicos básicos de todos los rellenos en aleros y cuevas. Este control cronológico, incluso contando con varios fechados, puede mostrar hiatos importantes aun en secuencias que no manifiestan discontinuidades estratigráficas marcadas (Mosquera 2018). La explicación para estos hiatos es variada, en algunos casos podría corresponder a procesos de remoción, generados por agentes naturales o antrópicos. A manera de ejemplo, en Agua de la Cueva sector norte, la remoción antrópica de sedimentos generó una discontinuidad temporal de unos 5000 años (Durán et al. 2020; Lucero et al. 2006). En otros casos, posiblemente más frecuente, las discontinuidades temporales responden a procesos de estabilidad ambiental en los que se generan horizontes de suelo (pedogénesis) o bien pueden responder a secuencias condensadas. Estas últimas son unidades relativamente delgadas que representan largos períodos bajo sedimentación mínima o nula, sin pedogénesis (O'Connor et al. 1999). Es decir que, en este caso, no existe remoción sino solo paso del tiempo. Un elemento datado en tal contexto proveería una edad puntual dentro del período prolongado de estabilidad representado en esa unidad. Al reactivarse la sedimentación, la siguiente edad obtenida por encima podría generar el hiato temporal. Por ejemplo, tanto en el Alero El Gaucho 1 como en Cueva Quebrada del Real 1 se pasa de un componente arqueológico del Holoceno Medio a otro del Holoceno Tardío en poco espesor, y sin que existan discontinuidades sedimentarias. No obstante, las diferencias en los fechados son de unos 3500 y 3000 ańos, respectivamente (Rivero 2009; Rivero et al. 2010; Rivero y Medina 2016). Otro aparente hiato puede originarse al no considerarse o muestrear la extensión lateral completa de una unidad estratigráfica (O'Connor et al. 1999), la cual puede variar o desaparecer en el plano horizontal (Farrand 1993). Los cambios laterales en la estratigrafía pueden estar relacionados con la topografía del fondo del alero o la cueva. Las partes más bajas permiten acomodar más sedimentos y presentan una sucesión con mayor continuidad que los sectores más elevados del fondo rocoso hacia donde estas unidades se acuñan con menor resolución. Ello parece haber ocurrido en Cueva Maripe, donde la cámara norte posee más relleno y una secuencia de edades con mayor continuidad respecto a la cámara sur, que muestra menos potencia y mayores discontinuidades temporales en el registro de ocupaciones (Miotti et al. 2014; Mosquera 2015).

Finalmente, la preservación excepcional de restos orgánicos como plumas y textiles también está relacionada con los microambientes particulares que se crean en aleros y cuevas, lo que hace que se recuperen restos que difícilmente se encuentren en otros contextos arqueológicos. Como ejemplos de sitios de nuestro país se pueden citar tres hallazgos que merecen destacarse: un conjunto de cientos de plumas de aves (López et al. 2015), un par de sandalias de cuero, una trenza de pelo humano y un sonajero de mate (Olivera et al. 2003), todos en cuevas del NOA y numerosos artefactos de cuero, pelos, vellones y tendones en un alero de Patagonia (Marchione y Bellelli 2013). También se ha registrado una excelente preservación de ADN antiguo en el material vegetal del Alero 1 PP9 (Winkel et al. 2018).

Es importante destacar en este punto que los rellenos de todos los sitios relevados corresponden al Holoceno, con la excepción de unos pocos que además incluyen depósitos del Pleistoceno 
Tardío (AEP-1, Cueva Amalia Sitio 2, Cueva Tixi, Gruta de Intihuasi y Alero La Enramada 3). Esto posee interesantes consecuencias para la arqueología de momentos tempranos y lleva a considerar algunas hipótesis:

A) La formación del reparo rocoso corresponde al finales del Pleistoceno y su sedimentación comienza en el Holoceno Temprano. En este caso se asume que se trata de aleros o cuevas relativamente recientes en la gran mayoría de los casos. Grandes cavidades pueden reflejar mucha mayor antigüedad y estabilidad (Farrand 2001a), como ocurre en la Gruta de Intihuasi que posee varios metros de relleno pleistoceno (al menos ocho) por debajo de la secuencia asignable al Holoceno (González 1960).

B) El reparo rocoso tiene un desarrollo bastante anterior al Holoceno, pero su relleno no lo refleja (v.g. pérdida de relleno antiguo, relleno no depositado por variadas causas o no detectado en la excavación). En relación con esta hipótesis, hay que tener en cuenta que en algunas ocasiones el relleno puede comenzar a acumularse bastante tiempo después de formada una cavidad, como se vio en el caso de los tafoni. Existen también otros mecanismos involucrados en el inicio de un relleno, como la presencia de vegetación en el frente de la cueva o alero que suele favorecer el entrampamiento y retención de sedimentos autóctonos y alóctonos. Otro ejemplo podría ser la presencia de estructuras de piedra antrópicas en los frentes de los reparos, que contribuyen al aumento de la tasa de depositación desde que se construyen, lo que puede haber ocurrido en cualquier momento de la secuencia de ocupación. Respecto a la pérdida de rellenos antiguos, una posibilidad es el «lavado» o remoción de sedimentos a partir de los cambios hidrológicos acaecidos entre el Pleistoceno Tardío y comienzos del Holoceno (v.g. mayor disponibilidad y circulación de agua en los sistemas serranos). Las cronologías pueden verse limitadas también por los sectores elegidos para realizar las excavaciones y sondeos (que quizás no detectaron los depósitos más antiguos) o, incluso, por considerar caídas de rocas como la base (falsa) de secuencias holocenas (O'Connor et al. 1999).

C) Durante el Holoceno se produjo el sellamiento o colapso de cuevas o aleros antiguos que poseían rellenos pleistocenos (ver Borrero et al. 2007 para el caso de Patagonia y Martínez 2007 para el caso de Tandilia en la Región Pampeana). Como soporte a esta idea, el incremento de los procesos de meteorización química durante el Holoceno pudo llevar al colapso de muchos reparos con rellenos previos. Eventos sísmicos importantes también pudieron colaborar con este proceso en zonas tectónicamente activas, hecho que se vería facilitado en el caso de aquellos afloramientos donde abundan fracturas irregulares y diaclasas. En la estratigrafía de la Cueva Amalia Sitio 2 se observan estructuras deformacionales (estratificación convoluta) que podrían vincularse con algún evento tectónico y/o con la caída de grandes bloques (Bonnat et al. 2015).

En suma, estas hipótesis, así como algunas otras, pueden comenzar a dar cuenta de la escasez de rellenos pleistocenos en las cuevas y aleros considerados, así como ayudan a orientar una búsqueda geoarqueológica de rellenos antiguos que puedan albergar sitios tempranos. Se debe tener en cuenta, además, que en algunas ocasiones las edades máximas a obtener en un alero pueden derivar de su contexto geomorfológico. El alero costero CL1 (Tierra del Fuego), se ubica en el tope de un antiguo acantilado que estuvo activo durante el Holoceno Medio (máximo transgresivo marino). De esta forma, el desarrollo de esta cavidad (tafone) debió ser posterior al retiro del mar de aquel sector. El talud debió asimismo evolucionar hasta alcanzar el reparo y posibilitar su acceso a los seres humanos. Todo ello acota temporalmente tanto el inicio del relleno de este alero como la cronología posible del registro de ocupaciones humanas en aquel contexto. Otro caso es el del Alero CHM2 (Santa Cruz), desarrollado en la pared de un bloque errático correspondiente al último avance glacial en la región (Pleistoceno Tardío), hecho que acota su relleno a partir del Tardiglacial en adelante. 


\section{Conclusiones preliminares}

Los aleros y cuevas analizados representan solo una forma transitoria de un proceso geomorfológico que avanza desde su profundización inicial hasta su colmatación, erosión o desplome. En ese sentido, estos reparos tienen una historia de vida con transformaciones en el espacio habitable, que es relativamente corta desde el punto de vista geológico y también desde el punto de vista arqueológico en muchos casos (Strauss 1990; Farrand 2001a; Borrero et al. 2007; Mentzer 2017). Sus trayectorias evolutivas, definidas por diversos factores, hacen que mientras algunos se estén ocultando otros vayan apareciendo. Su localización en diferentes contextos geológico-ambientales constituye un interesante laboratorio para el estudio de los procesos de meteorización-erosión que los generan, así como de su desarrollo y transformaciones, que poseen consecuencias para su uso antrópico. Se están empezando a evaluar algunos patrones vinculados a los tipos genéticos de aleros y cuevas someras, sus morfologías y algunas características de los rellenos resultantes en cada contexto. También se han comenzado a delinear algunas de sus propiedades cronológicas y de preservación. Si bien existen algunos sesgos específicos de estas geoformas, como los vinculados al inicio y preservación de sus rellenos, aleros y cuevas constituyen espacios de acumulación con mucho potencial para contribuir al panorama cronológico regional. Al respecto, es destacable que aproximadamente un $80 \%$ de los sitios con edades tempranas de la Argentina (entre 13,000 y 7000 ańos ${ }^{14} \mathrm{C} \mathrm{AP}$ ) corresponden a aleros y cuevas (Prates et al. 2013). Asimismo, estos reparos proveen valiosa información acerca de los modos de ocupación del espacio y utilización de recursos, que se suma a las evidencias procedentes de otras unidades del paisaje en cada región. Se considera que este análisis comparativo de los reparos rocosos, si bien limitado, adquiere valor como herramienta dirigida a la generación de expectativas arqueológicas y geoarqueológicas para su prospección y estudio. Se trata de un abordaje exploratorio que busca integrar los casos y opiniones de distintos investigadores que han trabajado o trabajan en este tipo de sitios. A partir de ello se espera aportar al conocimiento de patrones y procesos que nos ayuden a comprender los alcances y limitaciones de estos espacios para la interpretación arqueológica y tafonómica en cada área de estudio. Es deseable sumar más casos de las regiones analizadas, así como de otras que todavía no se han considerado, para obtener un panorama más amplio de la variabilidad de los reparos rocosos. Asimismo, se espera que se lleven a cabo proyectos integrativos similares en otros países de América Latina a fin de comparar resultados y aunar esfuerzos con objetivos comunes entre investigadores de la región.

\section{Agradecimientos}

A la doctora Cecilia Mauricio por organizar y editar la publicación de los trabajos presentados en el VII Taller del GEGAL (Lima) en este volumen especial, a las instituciones que financiaron los trabajos de campo de los sitios analizados en este trabajo y a la licenciada Daniela Storchi Lobos por la lectura crítica del manuscrito y el aporte de imágenes.

\section{Referencias}

Albino, A.M. y D.M. Kligmann (2007). An accumulation of bone remains of two Liolaemus species (Iguanidae) in an Holocene archaeological site of the Argentine Puna, Amphibia-Reptilia 28(1), 154-158. https://doi. org $/ 10.1163 / 156853807779799054$

Ambrústolo, P. y M. Ciampagna (2015). Alero 4 rock shelter, north coast of Deseado estuary (Patagonia, Argentina): hunter-gatherer mobility strategies during the Late Holocene, Quaternary International 373, 17-25. https:// doi.org/10.1016/j.quaint.2014.10.035

Ameghino, F. (1880-1881). La antigüedad del hombre en el Plata, Tomos I y II, Masson-Igon Hnos, París-Buenos Aires. 
Babot, M. P., C. A. Aschero, S. Hocsman, M. C. Haros, L. G. González Baroni y S. Urquiza (2006). Ocupaciones agropastoriles en los sectores intermedios de Antofagasta de la Sierra (Catamarca): un análisis desde Punta de la Peña 9.I, Comechingonia 9, 57-78. https://doi.org/10.37603/2250.7728.v9.n1.27615

Bar-Yosef, O., B. Vandermeersch, B. Arensburg, A. Belfer-Cohen, P. Goldberg, H. Laville, L. Meignen, Y. Rak, J. D. Speth, E. Tchernov, A-M. Tillier y S. Weiner (1992). The excavations in Kebara Cave, Mt. Carmel, Current Anthropology 33(5), 497-550. https://doi.org/10.1086/204112

Barberena, R., A. Blasi y C. Castiñeira (2006). Geoarqueología en Pali Aike: Cueva Orejas de Burro 1 (Patagonia, Argentina), Magallania 34(1), 119-138.

Bonnat, F., D. Mazzanti y G.A. Martínez (2015). Tecnología lítica y contexto geoarqueológico de la ocupación temprana del Sitio 2 de la localidad arqueológica Amalia, provincia de Buenos Aires (Argentina), Revista del Museo de Antropología 8(2), 21-32.

Borrero, L.A., R. Barberena, F.M. Martin y K. Borrazzo (2007). Collapsed rockshelters in Patagonia, en: M. Kornfeld, S. Vasilev y L. Miotti (eds.), On shelter's ledge: Histories, theories, and methods of rockshelter research, 135-139, BAR International Series 1655, Oxford.

Cabrera, A. L. (1976). Regiones fitogeográficas argentinas, en: Enciclopedia Argentina de Agricultura y Jardinería, Tomo II, Fascículo 1, Segunda edición, Editorial Acme, Buenos Aires.

Carbonelli, J. P., C. Belotti López de Medina, N. Carminatti, V. Peisker y D. Winocur (2019). La cueva Abra del Toro, espacio de las primeras ocupaciones durante el Holoceno en el valle de Yocavil, Libro de Resúmenes del XX Congreso Nacional de Arqueología Argentina, 178-182, Facultad de Filosofía y Letras, Universidad Nacional de Córdoba, Córdoba.

Carrera Aizpitarte, M. (2017). Primeros resultados de las investigaciones arqueológicas desarrolladas en el sector central de la sierra de San Luis (Argentina), Revista del Museo de Antropología, Suplemento Especial 1, 13-20.

Castro S. C. y V. Cortegoso (2010-2011). Ocupación temprana del norte de Mendoza: registro lítico del sitio Agua de la Cueva sector norte, Anales de Arqueología y Etnología 65-66, 9-36.

Cena Di Matteo, M., B. Bravo, Y. Morey y M. Carrera Aizpitarte (2018). Sitio La Angostura 1 (departamento Coronel Pringles, provincia de San Luis). Análisis de los conjuntos arqueológicos recuperados, Anales de Arqueología y Etnología 73(2), 99-132.

Chen, L., F. Guo, F. Liu, H. Xu, T. Ding y X. Liu (2019). Origin of tafoni in the Late Cretaceous aeolian sandstones, Danxiashan UNESCO Global Geopark, South China, Acta Geologica Sinica (English Edition) 93(2), 451-463. https://doi.org/10.1111/1755-6724.13810

Courty, M.A., P. Goldberg y R. Macphail (1989). Soils and Micromorphology in Archaeology, Cambridge University Press, Cambridge.

Curtoni, R., G. Gómez, M. Borgo, J. Chiesa, V. Lalinde, V. Martínez y A. Oliván (2017). Investigaciones arqueológicas en el sitio Alero Dupuy, provincia de San Luis, Revista del Museo de Antropología 10, 43-50. https://doi. org/10.31048/1852.4826.v10.n0.13526

Durán V., A. Gasco, J. Paiva, I. Zonana y R. Barberena (2020). El aprovechamiento de camélidos y ambientes de altura en sociedades agropastoriles prehispánicas del Noroeste de Mendoza (Argentina), Relaciones de la Sociedad Argentina de Antropologia, XLV(2), 271-296, Buenos Aires.

Etchichury, M.C. (1975). Sedimentología del perfil de el Alero de las Manos Pintadas, Relaciones de la Sociedad Argentina de Antropología N.S. IX, 177-185, Buenos Aires.

Eugenio, E. (1999). Geoarqueología de la cueva de «Las Buitreras» (Provincia de Santa Cruz, Argentina), Praehistoria 3, 135-145.

Farrand W. R. (1993). Discontinuity in the stratigraphic record: Snapshots from Franchthi Cave, en: P. Goldberg, D.T. Nash, y M.D. Petraglia (eds.), Formation Processes in Archaeological Context, 85-96, Monographs in World Archaeology 17, Prehistory Press, Madison.

Farrand W. R. (2001a). Archaeological sediments in rockshelters and caves, en: J.K. Stein y W.R. Farrand (eds.), Sediments in Archaeological Context, 29-66, The University of Utah Press, Salt Lake City.

Farrand W. R. (2001b). Sediments and stratigraphy in rockshelters and caves: a personal perspective on principles and pragmatics, Geoarchaeology 16(5), 537-557. https://doi.org/10.1002/gea.1004

Favier Dubois, C.M. (1998). Dinámica sedimentaria y cambios ambientales en relación al registro arqueológico y tafonómico del Cerro Cabeza de León, Bahía San Sebastián (Tierra del Fuego, Argentina), Anales del Instituto de la Patagonia, Serie Ciencias Humanas 26, 137-152.

Favier Dubois, C.M. (1999). Pedogénesis y formación de registros en Bahía San Sebastián (Tierra del Fuego) y Lago Roca (Santa Cruz), en: J. B. Belardi, P. Fernández, R. Goñi, G. Guráieb y M. De Nigris (comps.), Soplando en el viento... Actas de las 3as Jornadas de Arqueología de la Patagonia, 319-332, San Carlos de Bariloche. 
Favier Dubois, C.M. (2019). Human occupation chronologies modeled by geomorphological factors: a case study from the Atlantic coast of north Patagonia (Argentina), en: H. Inda Ferrero y F. García Rodríguez (eds.), Advances in Coastal Geoarchaeology in Latin America, 1-15, The Latin American Studies Book Series, Springer.

Favier Dubois C.M., D. Herrera Villegas, M. Cardillo, A.P. Alcaraz y P. Vitale (2020, ms.). Estudio geoarqueológico preliminar de la formación de aleros y sus rellenos en la localidad Punta Pórfido (Río Negro, Argentina), artículo en evaluación.

Fernández-Turiel, J.L., F.J. Pérez-Torrado, A. Rodríguez-González, J. Saavedra, J.C. Carracedo, M. Rejas, A. Lobo, M. Osterrieth, J. Carrizo, G. Esteban, J. Gallardo y N. Ratto (2019). The large eruption $4.2 \mathrm{ka} \mathrm{cal} \mathrm{BP} \mathrm{in} \mathrm{Cerro}$ Blanco, Central Volcanic Zone, Andes: Insights to the Holocene eruptive deposits in the southern Puna and adjacent regions, Estudios Geológicos 75(1), 1-31.

Franco, N. V. y L. A. Borrero (2003). Chorrillo Malo 2: initial peopling of the Upper Santa Cruz Basin, en: L. Miotti, M. Salemme y N. Flegenheimer (eds.), Where the south winds blow. Ancient evidences of paleo South Americans, 149-152, Center for the Studies of the First Americans (CSFA)/Texas A\&M University Press, Texas.

Goldberg, P. y S. C. Sherwood (2006). Deciphering human prehistory through the geoarcheological study of cave sediments, Evolutionary anthropology: Issues, news, and reviews 15(1), 20-36. https://doi.org/10.1002/ evan. 20094

Goldich, S.S. (1938). A study in rock weathering, Journal of Geology 46, 17-58. https://doi.org/10.1086/624619

González, A. R. (1960). La estratigrafía de la Gruta de Intihuasi, (Prov. de San Luis, R.A.) y sus relaciones con otros sitios precerámicos de Sudamérica, Revista del Instituto de Antropología 1, 5-296.

Goudie, A. S. (2004). Tafoni, en: A.S. Goudie (ed.), Encyclopedia of Geomorphology, 1034-1035, Routledge, Londres.

Groom, K. M., C.D. Allen, L. Mol, T. R. Paradise y K. Hall (2015). Defining tafoni: Re-examining terminological ambiguity for cavernous rock decay phenomena, Progress in Physical Geography 39(6), 775-793. https://doi. org/10.1177/0309133315605037

Hocsman S. y M. del P. Babot (2018). La transición de cazadores-recolectores a sociedades agropastoriles en Antofagasta de la Sierra (Puna de Catamarca, Argentina): perspectivas desde la agencia y las prácticas, Chungara. Revista de Antropología Chilena 50(1), 51-70.

Kligmann, D. M. (2009). Procesos de formación de sitios arqueologicos: Tres casos de estudio en la puna meridional catamarqueña Argentina, Archaeopress - British Archaeological Reports (BAR) International Series 1949, Oxford.

Kligmann, D. M., C. Sesé y J. Barbadillo (1999). Análisis tafonómico de la fauna de microvertebrados del Alero 12 (Puna meridional catamarqueña argentina) y sus implicancias para el comportamiento humano, Arqueología 9, 9-48.

Linse, A. R. (1992). Is bone safe in a shell midden?, en: J.K. Stein (ed.), Deciphering a shell midden, 327-345, Academic Press, San Diego.

López, G. E. J., F. I. Coloca, S. Araya, J. P. Orsi y S. Seguí (2015). El sitio Cueva Inca Viejo, Salar de ratones, Puna de Salta: evidencia arqueológica y procesos de interacción macroregional, Relaciones de la Sociedad Argentina de Antropología XL(1), 45-71.

Lucero, G. F., V. Cortegoso y S. C. Castro (2006). Cazadores-recolectores del Holoceno Temprano: explotación de recursos líticos en el sitio Agua de la Cueva sector norte, Anales de Arqueología y Etnología 61, 185-215.

Marchione, P. y C. Bellelli (2013). El trabajo del cuero entre los cazadores-recolectores de la Patagonia CentroSeptentrional. Campo Moncada 2 (valle medio del río Chubut), Relaciones de la Sociedad Argentina de Antropología 38, 223-246.

Martel, A. (2010a). Arte rupestre de pastores y caravaneros. Estudio contextual de las representaciones rupestres durante el período agroalfarero tardío (900 d.C.-1480 d.C.) en el Noroeste Argentino, tesis de doctorado, Facultad de Filosofía y Letras, Universidad de Buenos Aires, Buenos Aires.

Martel, A. (2010b). El Valle Encantado: un caso de análisis del arte rupestre y su relación con las prácticas rituales de los caravaneros, en: F. Oliva, N. de Grandis y J. Rodríguez (comps.), Argentina en los Inicios de un Nuevo Siglo, tomo III, 545- 553, Laborde Editor, Rosario.

Martínez, G.A. (2007). Procesos de formación de sitios en reparos rocosos de Tandilia, Cazadores-Recolectores del Cono Sur. Revista de Arqueología 3, 105-127.

Martínez G.A., D.L. Mazzanti, C. Quintana, A.F. Zucol, M.M. Colobig, G.S. Hassan, M. Brea y E. Passeggi (2013). Geoarchaeological and paleoenvironmental context of the human settlement in the Eastern Tandilia Range, Argentina, Quaternary International 299, 23-37. https://doi.org/10.1016/j.quaint.2012.12.032

Martínez, G.A. y M. Osterrieth (2001). Estratigrafía, procesos formadores y paleoambientes, en: D. Mazzanti y C. Quintana (eds.), Cueva Tixi: Cazadores y Recolectores de las Sierras de Tandilia Oriental, 1, Geología, 
Paleontología y Zooarqueología, 19-34, Laboratorio de Arqueología, Facultad de Humanidades, Universidad Nacional de Mar del Plata.

Martínez, G. A., M. Osterrieth y D. Mazzanti (2004). Ambiente de sedimentación y uso del espacio en la Localidad Arqueológica Amalia, Provincia de Buenos Aires, en: C. Gradin y F. Oliva (eds.), La Región Pampeana - Su Pasado Arqueológico, 61-72, Laborde Editor, Rosario.

Mazzanti, D. (1997). Excavaciones arqueológicas en el sitio Cueva Tixi, Buenos Aires, Argentina, Latin American Antiquity 8(10), 55-62. https://doi.org/10.2307/971592

McDonald, R.C. y C.R. Twidale (2011). On the origin and significance of basal notches or footcaves in karst terrains, Physical Geography 32(3), 195-216. https://doi.org/10.2747/0272-3646.32.3.195

Mehl, A. y N.V. Franco (2009). Cambios en la morfología de los reparos rocosos: el caso de los sitios Chorrillo Malo 2 y Río Bote 1 (Pcia. de Santa Cruz, Argentina), en: M. Salemme, M. Álvarez, F. Santiago y E. Piana (eds.), Arqueología de la Patagonia - Una mirada desde el Último Confin, tomo II, 893-900, editorial Utopías, Ushuaia.

Menghín, O.F. y M. Bórmida (1950). Investigaciones Prehistóricas en Cuevas de Tandilia (Prov. de Buenos Aires), Runa III: 5-36, Buenos Aires.

Mentzer, S.M. (2017). Rockshelter settings, en: A.S. Gilbert (ed.), Encyclopedia of Geoarchaeology, 725-743, Encyclopedia of Earth Sciences Series, Springer, Dordrecht.

Miotti, L., D. Hermo, L. Magnin, N. Carden, L. Marchionni, M.A. Alcaraz, B. Mosquera, E. Terranova y M. Salemme (2007). Resolución e integridad arqueológica en la Cueva Maripe (Santa Cruz, Argentina), en: M.T. Civalero, P.M. Fernández y A.G. Guráieb (comps.), Contra viento y marea. Arqueología de Patagonia, 555-568, Instituto Nacional de Antropología y Pensamiento Latinoamericano, Buenos Aires.

Miotti, L., L. Marchionni, B. Mosquera, D. Hermo y A. Ceraso (2014). Fechados radiocarbónicos y delimitación temporal de los conjuntos arqueológicos de Cueva Maripe, Santa Cruz (Argentina), Relaciones de la Sociedad Argentina de Antropología XXXIX(2), 509-537, Buenos Aires.

Mosquera, B. (2015). Geoarqueología del sitio Cueva Maripe, Macizo del Deseado, Provincia de Santa Cruz, Argentina, Comechingonia 19(1), 155-182, Córdoba.

Mosquera, B. (2018). Análisis de la información radiocarbónica de sitios arqueológicos del Macizo del Deseado, provincia de Santa Cruz, Argentina, Intersecciones en Antropología 19, 25-36, Olavarría.

O'Connor S., P. Veth y A. Barham (1999). Cultural versus natural explanations for lacunae in Aboriginal occupation deposits in northern Australia, Quaternary International 59, 61-70. https://doi.org/10.1016/S10406182(98)00072-X

Ojeda, G. y O. Pedersen (2019, ms.). Estudios geomorfológicos en la gruta Intihuasi. Plan y Protocolo de Manejo de la Gruta de Intihuasi. Informe III. Convenio Universidad Nacional de San Luis-Gobierno de la Provincia de San Luis.

Olivera, D.E., A.S. Vidal y L.G. Grana (2003). El sitio Cueva Cacao 1A: Hallazgos, espacio y proceso de complejidad en la Puna meridional (ca. 3000 años A.P.), Relaciones de la Sociedad Argentina de Antropología XXVIII, 257-270, Buenos Aires.

Osterrieth, M.L., G.A. Martínez, A. Zucol, M. Brea y D. Mazzanti (2002). Procesos de formación del Sitio 2 de la Localidad Arqueológica Amalia, provincia de Buenos Aires, en: D. Mazzanti, M. Berón y F. Oliva (eds.), Del mar a los salitrales. Diez Mil años de historia pampeana en el umbral del tercer milenio, 343-354, UNMDP/ LARBO y SAA, Mar del Plata.

Oyarzabal, M., J. Clavijo, L. Oakley, F. Biganzoli, P. Tognetti, I. Barberis, H.M. Maturo, R. Aragón, P.I. Campanello, D. Prado, M. Oesterheld y R.J.C. León (2018). Unidades de vegetación de la Argentina, Ecología Austral 28(1), 40-63, Buenos Aires.

Pereyra, F.X. y A.G. Guráieb (1998). Procesos naturales de formación de sitios en aleros: Cerro de los Indios 1 (Lago Posadas, Santa Cruz), Arqueología 8, 101-126.

Pope, G.A., R.I. Dorn y J.C. Dixon (1995). A new conceptual model for understanding geographical variations in weathering, Annals of the Association of American Geographers 85, 38-64.

Prates, L., G. Politis y J. Steele (2013). Radiocarbon chronology of the early human occupation of Argentina, Quaternary International 301, 104-122. https://doi.org/10.1016/j.quaint.2013.03.011

Rafuse D.J. y A. Massigoge (2020). Abrigo La Tinta: Preliminary results of a New Late Pleistocene-Early Holocene rockshelter from the Pampas Region (Tandilia Range), Argentina, PaleoAmerica 6(3), 299-301, https://doi. org/10.1080/20555563.2019.1684047 https://doi.org/10.1080/20555563.2019.1684047

Retallak, G.J. (1990). Soils of the past. An introduction to paleopedology, Harper Collins Academic, Londres.

Rivero, D. (2009). Ecología de cazadores-recolectores del sector central de las Sierras de Córdoba (Rep. Argentina), BAR International Series 2007, British Archaeological Reports, Oxford. 
Rivero, D. (2017). Informe de las investigaciones arqueológicas realizadas en el sitio Los Morteros (PNQC, prov. de Córdoba), Administración de Parques Nacionales, Delegación Regional Centro, Córdoba, Argentina.

Rivero, D., V. Franco Salvi y H. Paradela (2008). Cambios en la funcionalidad del sitio Arroyo El Gaucho 1 durante el Holoceno (pcia. de Córdoba, Argentina), Arqueología 14, 77-101.

Rivero, D. y G. Heider (2020). El paisaje social del centro de Argentina durante la transición Pleistoceno-Holoceno (ca. 11.000-9000 AP), Arqueología 26(1), 109-126. https://doi.org/10.34096/arqueologia.t26.n1.5803

Rivero, D. y M. Medina (2016). Human Holocene colonization, diet breadth and niche construction in Sierras of Córdoba (Argentina), en: M. Cardillo y H. Muscio (eds.), Darwin's Legacy: The Status of Evolutionary Archaeology in Argentina, 67-82, South American Archaeology Series 24, Archaeopress Publishing Ltd., Oxford.

Rivero, D., S. Pastor y M. Medina (2010). Intensificación en las Sierras de Córdoba. El abrigo rocoso Quebrada del Real 1 (ca. 6000-500 AP, Córdoba, Argentina), Anales de Arqueología y Etnología 63-64, 227-246, Mendoza.

Scasso, R.A. y E.O. Eugenio (1999). Estudio sedimentológico de la cueva Las Buitreras (Provincia de Santa Cruz, Argentina), Praehistoria 3, 147-161, Buenos Aires.

Straus, L.G. (1990). Underground archaeology: Perspectives on caves and rockshelters, en: M.B. Schiffer (ed.), Archaeological method and theory 2, 255-304, University of Arizona Press, Tucson.

Turkington, A. (2004). Cavernous weathering, en: A.S. Goudie (ed.), Encyclopedia of geomorphology, 128-130, Routledge, Londres.

Turkington, A.V. y J. Phillips (2004). Cavernous weathering, dynamical instability and self-organization, Earth Surface Processes and Landforms 29(6), 665-675. https://doi.org/10.1002/esp.1060

Waters, M.R. (1992). Principles of geoarchaeology: A North American perspective, University of Arizona Press, Tucson.

Winkel, T., M.G. Aguirre, C.M. Arizio, C.A. Aschero, M.d.P. Babot, L. Benoit, C. Burgarella, S. Costa-Tártara, M.P. Dubois, L. Gay, S. Hocsman, M. Jullien, S.M.L. López Campeny, M.M. Manifesto, M. Navascués, N. Oliszewski, E. Pintar, S. Zenboudji, H.D. Bertero y R. Joffre (2018). Discontinuities in quinoa biodiversity in the dry Andes: An 18-century perspective based on allelic genotyping, PLoS ONE 13(12): e0207519, https:// doi.org/10.1371/journal.pone.0207519

Zárate, M., A. Blasi y J. Rabassa (2000). Geoarqueología de la localidad Piedra Museo. Guía de Campo de la visita a las localidades arqueológicas, en: L. Miotti, R. Paunero, M. Salemme y G. Cattáneo (eds.), Taller internacional del INQUA «La Colonización del sur de América durante la transición Pleistoceno/Holoceno», 56-64, La Plata-Río Gallegos.

Zubimendi M.A. y P. Ambrústolo (2016). Estudio comparativo de abrigos rocosos en la costa norte de Santa Cruz (Patagonia), Comechingonia 20(1), 253-276. https://doi.org/10.37603/2250.7728.v20.n1.17945

Recibido: 25/06/2020

Aprobado: 12/01/2020 